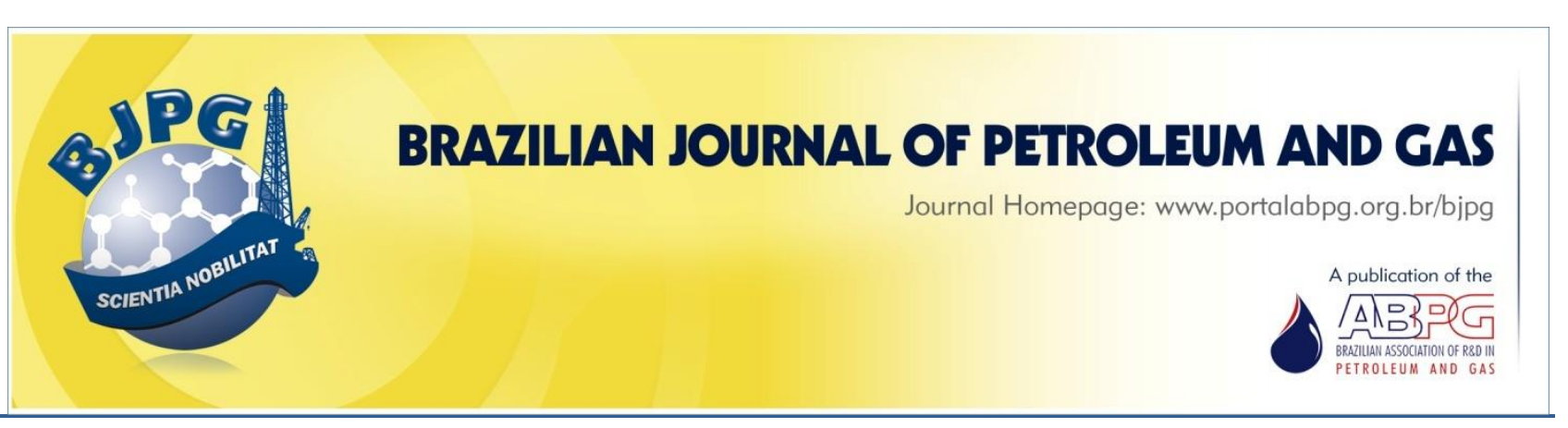

\title{
SENSITIVITY ANALYSIS FOR POLYMER INJECTION TO IMPROVE HEAVY OIL RECOVERY - SMALL-SCALE SIMULATION STUDY
}

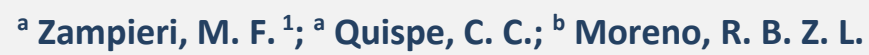 \\ a University of Campinas (UNICAMP), Center for Petroleum Studies (CEPETRO), Campinas - SP, Brazil \\ ${ }^{b}$ University of Campinas (UNICAMP), School of Mechanical Engineering, Campinas - SP, Brazil \\ Received: 11.09.2020 / Revised: 05.11.2020 / Accepted: 08.11.2020 / Published on line: 07.01.2021
}

\begin{abstract}
Polymer flooding has been widely used for enhancing oil recovery, due to the growing number of successful applications around the world. The process aims to increase water viscosity and, thus, decrease the water/oil mobility ratio, thereby improving sweep efficiency. The understanding of the physical mechanisms involved in this enhanced oil recovery process allows us to forecast the application potential of polymer flooding. This work aims to assess physical phenomena associated with heavy oil recovery through polymer flooding using 1D small-scale simulation models. We evaluate the influence of different levels of adsorption, accessible pore volume, residual resistance factor, and polymer concentration on the results and compare their magnitude effect on the results. The models used in this study were built using data from previous lab work and literature. For each one of the mentioned parameters, this work compares the histories of water cut, cumulative water-oil ratio, average pressure, and oil recovery factor. Additionally, water saturation, water viscosity, and water mobility profile were determined for specific periods of the flooding process. The sensitivity analyses showed that high levels of adsorption influence the polymer loss of the advance front, delaying oil recovery. Low values of accessible pore volume lead to a slightly faster polymer breakthrough and oil recovery anticipation. A high residual resistance factor increases the average pressure and improves oil recovery. Higher polymer concentration enhances the displacement efficiency and enhances the recovery factor.
\end{abstract}

\section{KEYWORDS}

enhanced oil recovery; polymer flooding; simulation; heavy oil; sensitivity analysis

\footnotetext{
${ }^{1}$ To whom all correspondence should be addressed. Address: University of Campinas (UNICAMP), Center for Petroleum Studies (CEPETRO), Cidade Universitária "Zeferino Vaz" s/n, Campinas - SP, Brazil ZIP Code: 13083-970 | e-mail: marcelofzampieri@gmail.com doi:10.5419/bjpg2020-0018
} 


\section{INTRODUCTION}

As global needs for sustainable projects increase, polymer-flooding for enhanced oil recovery has become an attractive opportunity. This scenario is mainly due to oil recovery anticipation and injected/produced water reduction, compared to the conventional waterflooding method.

The polymer-flooding method has been successfully applied in heavy-oil reservoirs, especially in cases where thermal methods are not suitable. For instance, some heavy-oil deposits in western Canada are so thin that thermal methods cannot be applied efficiently (Jamaloei et al., 2010). Excessive heat loss is also a challenge for deep reservoirs, opening up opportunities for polymer injection.

Viscous-oil reservoirs present several challenges for polymer-flooding. One of the main issues is the ability to design a high viscous polymer solution while avoiding injectivity problems. Seright (2010) states that reduced injectivity can limit polymerflooding of viscous oils more than chemical costs. However, the use of horizontal wells has mitigated concerns about low injectivity of large viscous slugs, therefore, turning polymer-flooding more technically feasible and profitable.

Simulation models have a relevant role in evaluating potential production and profitability of sophisticated techniques such as polymer-flooding. A precise simulation relies on accurate laboratory data and reliable representation of its physical phenomena. Therefore, rheology experiments, single-phase and two-phase core flooding tests, are necessary to determine the properties associated with the polymer flow through porous media. Among these properties, the most important are adsorption, inaccessible pore volume, residual resistance factor, fluids viscosity, and relative permeabilities.

The comprehension of polymer behavior using simulation model can assist in the history matching process and complement the data of core flooding tests, such as the fluid displacement over the sample. Moreover, the evaluation of laboratory outcomes through numerical modeling can give insights on how accurate a field-scale reservoir simulation and its corresponding risk assessment are.
Many authors have gathered experimental studies and numerical simulations of polymer flooding, including non-Newtonian models, in oil recovery process disclosed in the open literature (Seright, 2010; Fabbri et al., 2013; Hatzignatiou et al., 2013b; Sheng, 2013; Lamas et al. 2016; Zampieri et al., 2020). This work relies on a comprehensive observation of fluids displacement into porous media with polymer injection, assessing the shock fronts, including formation water and injected solution.

We performed this work in a core-scale nonNewtonian model, relying on maintenance of the fidelity of laboratory design and understanding of the physical phenomena in 1D. The description of the model and the main equations involved are presented. We developed sensitivity analyses (SA) based on laboratory experiments. The uncertainties were based on values found in literature, aiming at determining the effects of adsorption (ADS), accessible pore volume (APV), residual resistance factor (RRF), and polymer concentration (CCP) on recovery results.

\subsection{Adsorption - ADS}

Adsorption is the interaction between polymer molecules and rock surface, depending on its affinities. This interaction causes polymer molecules to be bound to the rock surface mostly by physical adsorption - van der Waals forces and hydrogen bonding - that is weak and forms no chemical bonding (Sheng, 2011). Regarding polymer physical features, molecular size and average molecular weight act on adsorption. Moreover, salinity, $\mathrm{pH}$, and hardness of the used solvent are related strongly to the adsorption degree as well (Sorbie, 1991).

The rock surface adsorbs some polymer molecules from the injected solution, lowering its concentration and, consequently, reducing the fluid's viscosity. On the one hand, this reduction of polymeric solution viscosity has an adverse effect on mobility ratio, thus, decreasing oil recovery potential. It is essential to consider the water permeability reduction caused by the polymer retention (Jennings et al., 1971; Carcoana, 1992; Grattoni et al., 2004), which contributes to mobility ratio's reduction.

Table 1 shows some values of adsorption level of HPAM polymer, reported in the literature at different concentrations. 
Table 1. Maximum adsorption per concentration.

\begin{tabular}{lcc}
\hline \hline \multicolumn{1}{c}{ Source } & $\begin{array}{c}\text { Concentration } \\
(\mathbf{p p m})\end{array}$ & $\begin{array}{c}\text { Adsorption } \\
(\boldsymbol{\mu g} / \mathrm{g})\end{array}$ \\
\hline \hline Willhite and Dominguez (1977) & $100-500$ & $10-21$ \\
Osterloh and Law (1998) & 500 & $10-20$ \\
Zheng et al. (1998) & $250-1500$ & $40-58$ \\
Choi (2008) & 5000 & $76-382$ \\
Salazar (2009) & $1750-2250$ & $109.7-208.2$ \\
Hatzignatiou et al. (2013b) & 400 & $1.92-42.41$ \\
Delamaide et al. (2013) & $500-1000$ & 12 \\
Manichand and Seright (2014) & $1000-2300$ & $50-250$ \\
\hline \hline
\end{tabular}

Sorbie (1991) stated that the level of polymer retention is one of the fundamental factors to assess the economic feasibility of polymer flooding. In a dynamic-flooding test, the total polymer loss or polymer retention comprises the mechanical entrapment, hydrodynamic retention, and adsorption. The amount of oil recovered per mass of injected polymer is related inversely to polymer retention.

Polymer adsorption is usually the major cause of polymer retention. We can restrict the retention to polymer adsorption in a simulation model. The simulator can represent polymer adsorption by adsorption isotherms, which are used to estimate, at a given temperature, the amount of adsorbed polymer related to the polymer concentration. There are different models of isotherms, such as Langmuir isotherm, Henry isotherm, Freundlich isotherm, and Concave isotherm.

The Langmuir-type isotherm is one of the most used models to quantify polymer adsorption at the solid surface (Lake, 1989; Aluhwal, 2008; Mohammadi, 2008; Wang, 2009; Sheng, 2011). It can be represented by the following equation:

$\hat{C}_{p}=\frac{a_{p} C_{p}}{1+b_{p} C_{p}}$

$C_{p}$ is the polymer concentration on the liquid phase, $\hat{C}_{p}$ is the polymer adsorbed in the rock, and $a_{\mathrm{p}}$ and $b_{p}$ are constants for a given rock-fluid system at a specific temperature.

Figure 1 shows a typical shape of Langmuir-type isotherm, where $b_{\mathrm{p}}$ determines the curvature of the isotherm and the ratio $a_{\mathrm{p}} / b_{p}$ controls the plateau value of the adsorption (Lake, 1989).
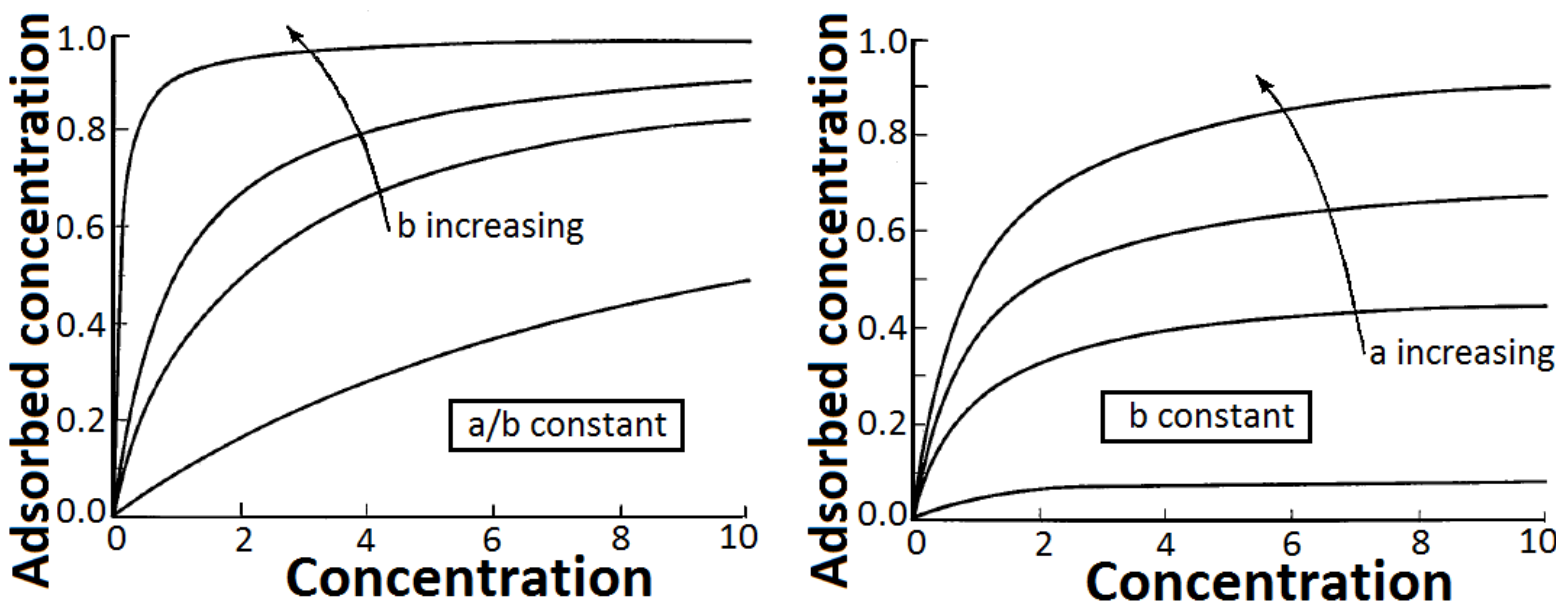

Figure 1. Typical shape of the Langmuir isotherm (adapted from Lake, 1989). 
Adsorption is used as an instantaneous effect in the model, which results in a stripped water bank at the leading edge of the slug (Aluhwal, 2008).

\subsection{Accessible Pore Volume - APV}

The accessible pore volume parameter defines the effective pore volume for the polymer macromolecule flow in porous media. Dawson and Lantz (1972) were the first to report this phenomenon. Conceptually, a polymer molecule is not able to flow through the entire pore space; it only travels through the accessible portion which accelerates its arrival at the outlet face or producer well. Sorbie (1991) developed models that reflect this concept.

In fact, both the pore throats and the polymer molecule do not have absolute sizes, but a range of values. Statistically, there is a combination of molecule sizes that passes through a combination of pore throat. If the size of the molecule is equal to or bigger than the pore throat, it does not go through this pore, and this porous portion is called inaccessible pore volume (IPV) (Dawson \& Lantz, 1972). The APV is commonly represented by a fraction of the total pore volume, which is defined as one minus the fraction of IPV.

The magnitude of the inaccessible pore volume depends more on polymer type and porous medium than on polymer concentration, salinity, and the remaining oil in the porous medium (Lötsch et al., 1985).

Many authors noted that, in lab tests, when no retention is observed, polymer molecules are transported through porous media more quickly than the inert chemical tracer dissolved in the injected polymer solution, because of the IPV. The dispersion of the tracer coefficient has at the same value as the water solvent (Dawson \& Lantz, 1972; Lötsch et al., 1985; Lake, 1989; Sorbie, 1991).

Two explanations have been reported to explain the fact that the polymer moves faster than the tracer. One considers that large polymer molecules do not pass into small and dead-end pores, flowing only through bigger pores. Thus, polymer molecules propagate faster than the tracer substance. The second hypothesis relates to the wall-exclusion effect of the flow regime. Under this effect, polymer molecules concentrate and flow in the center of the porous channels of the reservoir rock. This effect occurs because the streamlines away from the wall are associated with the higher velocities. Such flow behavior accelerates the polymer to move on average velocity faster than the chemical tracer through the porous media (Lake, 1989; Sorbie, 1991).

Lötsch et al. (1985) injected a bank of biopolymer solution (Scleroglucan and Xanthan) and a tracer through a sandstone-core. After polymer and tracer outlet concentrations reached their respectively injected levels, brine was pumped (post flood) to displace all mobile polymer and tracer. Then, the second bank of polymer solution containing tracer was injected, and polymer retention and inaccessible pore volume were determined using only the front part of the effluent curves, resultant of the two injection stages. Inaccessible pore volume (IPV) was measured during the second injection cycle from the difference in area between polymer breakout and tracer breakout curves.

Manichand and Seright (2014) determined IPV from Equation 2.

$I P V=\Sigma[($ Cpoly/Cpolyo * $\Delta P V)-($ Ctrac/Ctraco $* \Delta P V)]$

The authors also determined polymer retention (Equation 3) during the first injection cycle from the difference in area between the polymer breakout and the tracer breakout curves.

$R=\{[\Sigma[($ Cpoly/Cpolyo $* \Delta P V)-($ Ctrac/Ctraco $*$ $\triangle P V)]]+I P V\} *$ Cpolyo ${ }^{*} P V /$ Mrock

$R$ is the polymer retention in $\mu \mathrm{g} / \mathrm{g}$, Cpoly is effluent polymer concentration, Ctrac is the effluent tracer concentration, Cpolyo is the injected polymer concentration, Ctraco is the injected tracer concentration, $P V$ is the pore volume, $\triangle P V$ is the pore-volume increment, and Mrock is the mass of the core.

Differently, low APV requires a low amount of polymer, reducing the cost of the process and presenting advantages. In contrast, too low APV may impair the recovery process (Melo, 2008).

Table 2 shows some values of IPV of HPAM polymer, described in the literature at different porous media, permeability, and salinity. Some data are a complement to that shown previously in the adsorption item (Table 1). 
Table 2. IPV values from the literature.

\begin{tabular}{|c|c|c|c|c|}
\hline Source & $\begin{array}{l}\text { Porous } \\
\text { Medium }\end{array}$ & $\mathrm{k}, \mathrm{md}$ & $\begin{array}{c}\text { Salinity, } \\
\% \text { TDS }\end{array}$ & $\begin{array}{c}\text { IPV, } \\
\%\end{array}$ \\
\hline $\begin{array}{c}\text { Dawson and Lantz } \\
(1972) \\
\end{array}$ & Berea & 470 & $1-2$ & 22 \\
\hline $\begin{array}{c}\text { Dawson and Lantz } \\
(1972) \\
\end{array}$ & Bartlesville & 2090 & $1-2$ & 24 \\
\hline Knight et al. (1974) & Berea & $\begin{array}{l}90- \\
120 \\
\end{array}$ & 0.05 & $\begin{array}{c}0- \\
4 \\
\end{array}$ \\
\hline $\begin{array}{c}\text { Willhite and } \\
\text { Dominguez (1977) }\end{array}$ & Teflon & 86 & 2 & 19 \\
\hline $\begin{array}{l}\text { Osterloh and Law } \\
\text { (1998) }\end{array}$ & Sandpack & $\begin{array}{c}2500 \\
- \\
11000\end{array}$ & 1.3 & $\sim 20$ \\
\hline Choi (2008) & Berea & $\begin{array}{c}629- \\
593 \\
\end{array}$ & 3 & $\begin{array}{l}14- \\
27\end{array}$ \\
\hline $\begin{array}{c}\text { Pancharoen et al. } \\
(2010)\end{array}$ & Sandpack & 12600 & - & $\sim 30$ \\
\hline $\begin{array}{c}\text { Hatzignatiou et al. } \\
(2013 a)\end{array}$ & Berea & $\begin{array}{c}758- \\
842 \\
\end{array}$ & - & $\begin{array}{l}7- \\
15 \\
\end{array}$ \\
\hline $\begin{array}{l}\text { Manichand and } \\
\text { Seright (2014) }\end{array}$ & Sandpack & $\begin{array}{c}401- \\
877\end{array}$ & 0.0005 & $\sim 0$ \\
\hline
\end{tabular}

\subsection{Residual Resistance Factor - RRF}

RRF is a parameter used to indicate the decrease of water mobility after polymer flooding, relative to the water flow before the flow of the polymer solution (Carcoana, 1992).

In order to describe only the permeability reduction effect, a permeability reduction factor $\left(R_{k}\right)$ is defined as the ratio between relative permeability to water $\left(k_{w}\right)$ and polymer fluid $\left(k_{p}\right)$ :

$R_{k}=\frac{k_{w}}{k_{p}}$

The contribution of the mobility reduction achieved by the polymeric fluid, including viscosity increase and permeability reduction effects, is known as resistance factor $\left(R_{F}\right)$. It is defined as the ratio between water $\left(\lambda_{w}\right)$ and polymer fluid $\left(\lambda_{p}\right)$ mobilities:

$R_{F}=\frac{\lambda_{w}}{\lambda_{p}}=\frac{k_{w} / \mu_{w}}{k_{p} / \mu_{p}}$

$\mu_{w}$ and $\mu_{p}$ are water and polymer fluid viscosities, respectively.

Even when applying water flooding in the porous media after a polymer slug, a residual resistance to flow still remains. The residual resistance factor (RRF) is given by the ratio between water mobility before $\left(\lambda_{w 1}\right)$ and after $\left(\lambda_{w 2}\right)$ the flow of the polymeric slug.

$\mathrm{RRF}=\frac{\lambda_{w 1}}{\lambda_{w 2}}=\frac{k_{w 1} / \mu_{w}}{k_{w 2} / \mu_{w}}=\frac{k_{w 1}}{k_{w 2}}=\frac{P_{2}}{P_{1}}$

$P_{1}$ and $P_{2}$ are the pressure drop before and after the polymer flooding respectively.

Although the resistance factor $R_{F}$ is a parameter to evaluate polymer ability to sweep the oil from the reservoir, it is rarely used due to limitations to estimate polymer mobility. The $R_{F}$ is a function of the permeability to the polymer, which is calculated from Darcy's equation.

The residual resistance factor is used more frequently to make comparisons between laboratory and field data, than to assess resistance factor, because it is simpler, more directly accessible, and devoid calculation simplifications (Silva et al., 2010).

Delamaide (2014) stated that in highly permeable formations, RRF can be low (close to 1); values in the 2-4 range are common, but higher values suggest that the polymer molecules may be too large for the formation. Osterloh and Law (1998) core-flood results indicate that RRF would 


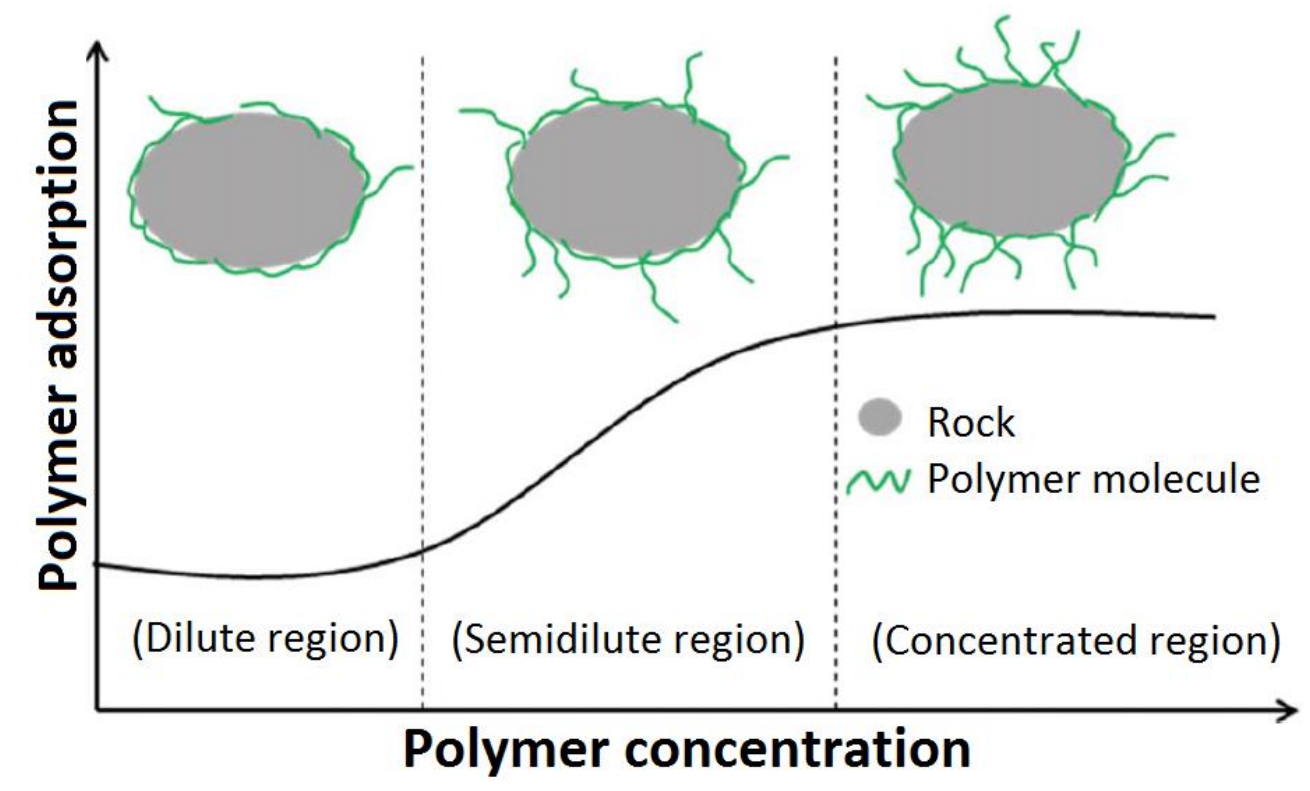

Figure 2. Polymer-adsorption mechanism per concentration on the rock surface (adapted from Zhang and Seright, 2014).

be between three-to-five at most, but possibly lower. Zampieri (2012) found values of RRF of 2.62 for highly permeable sandstones.

\subsection{Concentration}

Polymer concentration is a crucial parameter in the design of an efficient polymer flooding project. Due to the high cost of polymers, it is essential to optimize polymer injection strategies to perform the greatest oil recovery at the lowest cost for the project. The optimum concentration of the injected polymer solution has a direct impact on the optimization process, maximizing profit and cumulative oil production (Lei et al., 2012; Sheng et al., 2015).

Each type of polymer provides a specific increase of fluid viscosity (Sorbie, 1991). A higher target polymer viscosity can be reached by increasing polymer concentration. Wang and Dong (2007) claimed that a lower concentration of polymer solution can be strategically implemented if polymer flooding is applied at an earlier stage of the production life of a heavy-oil reservoir.

Polymer concentration increase is more effective on the incremental oil recovery because polymer concentration reduces the mobility ratio of water/oil directly by increasing the water-phase viscosity and reducing the effective permeability to water.

Zhang and Seright (2014) investigated how polymer concentration affects retention in porous media for both dynamic and static measurements. They state that if a rock surface is first contacted with dilute HPAM solution to fill the retention, no substantial additional retention takes place when subjected to higher concentrations (Figure 2). In field applications, reduced polymer retention may be achieved by first injecting a slug of low polymer concentration.

De Bons and Braun (1995), between 1975 and 1992, reviewed twelve pilots and field applications of polymer-flooding around the world. These projects were analyzed and compared with polymer-flooding conducted in the US between 1980 and 1993. The authors stated that the average concentration of polymer injected in US projects was 460 ppm vs. 920 ppm for the polymerflooding used abroad. The median incremental oil recovery through polymer flooding for the US was $4.9 \%$ OOIP, while the successful international incremental recovery accounted for 6 - 52\% OOIP.

The Daqing Field pilot tests started in 2001 using high molecular weight and high polymer concentration in three blocks: WN block, WM block, and E N1 block. These pilot areas began with polymer flooding of 16 million molecular weight (MW) and $1000 \mathrm{ppm}$. Then, after injecting polymer of 25 million MW and about 2000 ppm, the water cut was reduced by 25 to $30 \%$. After the positive results obtained from these pilots, a large-scale polymer flooding was applied to the E W N1 blocks 
Table 3. Summary of input parameters.

\begin{tabular}{|c|c|c|}
\hline Information & Parameter & Value \\
\hline \multirow{6}{*}{ Formation Properties } & Rock density & $2.65 \mathrm{~kg} / \mathrm{cm}^{3}$ \\
\hline & Porosity (homogeneous) & $28 \%$ \\
\hline & Permeability (homogeneous) & $5500 \mathrm{mD}$ \\
\hline & Core length & $31.6 \mathrm{~cm}$ \\
\hline & Cross-Sectional Area & $10.75 \mathrm{~cm}^{2}$ \\
\hline & Pore Volume & $95.12 \mathrm{~cm}^{3}$ \\
\hline \multirow{7}{*}{ Fluid Properties } & Oil density & $9.62 \times 10^{-4} \mathrm{~kg} / \mathrm{cm}^{3}$ \\
\hline & Oil viscosity & $180 \mathrm{cP}$ \\
\hline & Water density & $1.08 \times 10^{-3} \mathrm{~kg} / \mathrm{cm}^{3}$ \\
\hline & Water viscosity & $1.2 \mathrm{cP}$ \\
\hline & Polymer solution density & $1.10 \times 10^{-3} \mathrm{~kg} / \mathrm{cm}^{3}$ \\
\hline & Polymer viscosity vs Concentration & Figure 3 \\
\hline & Polymer viscosity vs. Shear rate & Figure 4 \\
\hline \multirow{6}{*}{ Rock-fluid interaction } & Relative Permeability Curves & See Eq. 5 and 6 \\
\hline & Residual water saturation & $5 \%$ \\
\hline & Residual oil saturation & $25 \%$ \\
\hline & Polymer Adsorption - Langmuir & SA - Figure 5 \\
\hline & Residual Resistance Factor (RRF) & SA \\
\hline & Accessible pore volume & SA \\
\hline \multirow{4}{*}{ Initial Conditions } & Initial pressure & $101.3 \mathrm{kPa}$ \\
\hline & Initial temperature & $22.8^{\circ} \mathrm{C}$ \\
\hline & Initial Oil Saturation & $95 \%$ \\
\hline & Initial water saturation & $5 \%$ \\
\hline \multirow{4}{*}{ Operational conditions } & Injection rate & $0.4 \mathrm{~cm}^{3} / \mathrm{min}$ \\
\hline & Polymer Concentration & SA \\
\hline & Minimum pressure at producer well & $101.3 \mathrm{kPa}$ \\
\hline & Simulation period & $95 \%$ of Wcut \\
\hline
\end{tabular}

in January 2009. Polymer MW was 25 million, and injected concentration was 2030 ppm. Injected polymer solution was $0.61 \mathrm{PV}$. Water cut was significantly reduced and incremental oil recovery was more than $10 \%$ (Sheng, 2013).

The polymer flooding in the East Bodo heavy-oil reservoir in Canada began in May 2006. The oil viscosity was 600-2000 cP (140 API). It was expected that the polymer solution injected (1500 ppm) would result in $25 \mathrm{cP}$. However, reservoir solution viscosity was $10 \mathrm{cP}$ at maximum. So later, a fresher water source with 3700 ppm of TDS was applied, and the solution viscosity of $1500 \mathrm{ppm}$ reached $60 \mathrm{cP}$ at the surface. Polymer concentration at the nearest producing wells was about $100 \mathrm{ppm}$. The pilot performance indicated that for polymer flooding in the heavy-oil reservoir, horizontal wells alleviated the injectivity problem (Sheng, 2013).

\section{METHODOLOGY}

This section describes the procedures used for building the simulation models. We carried out the core-scale models using the CMG-STARS ${ }^{\circledR}$ commercial simulator. We generated the conceptual model with data from previous lab experiments (Zampieri \& Moreno, 2013; Silveira et al., 2016).

Table 3 summarizes the main input parameters for formation properties, initial and operational conditions, fluid properties, and rock-fluid interaction of the conceptual model.

Rock properties of simulation models were based on two-phase displacement tests performed by Zampieri and Moreno (2013). The model is a synthetic core-sandstone representing the porous media by homogeneous porosity and permeability.

Figure 3 shows the polymer viscosity for different polymer concentrations of the solution at $7.848 \mathrm{~s}^{-1}$ of shear rate (Silveira et al., 2016) and the function used in the simulation model. The bulk viscosity vs. concentration of the polymer solution was determined through a rotational rheometer with concentric cylinders geometry by Silveira et al. (2016). The CMG-STARS simulator uses a 


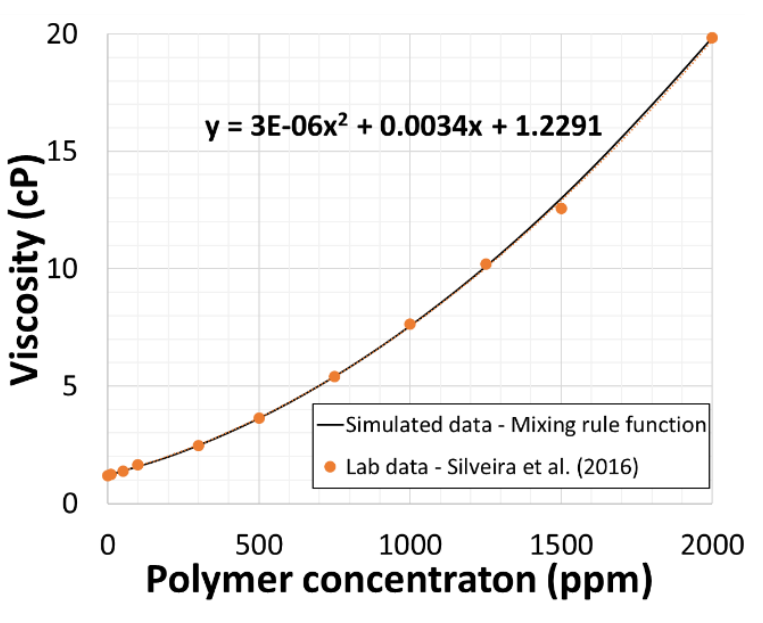

Figure 3. Viscosity vs concentration.

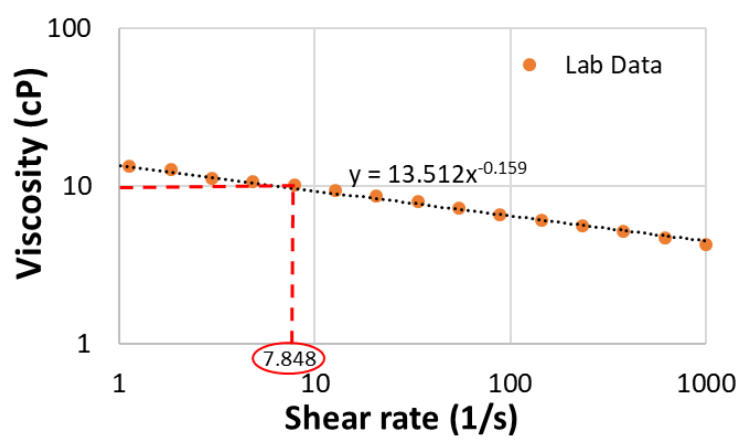

Figure 4. Viscosity vs shear rate (adapted from Silveira et al., 2016).

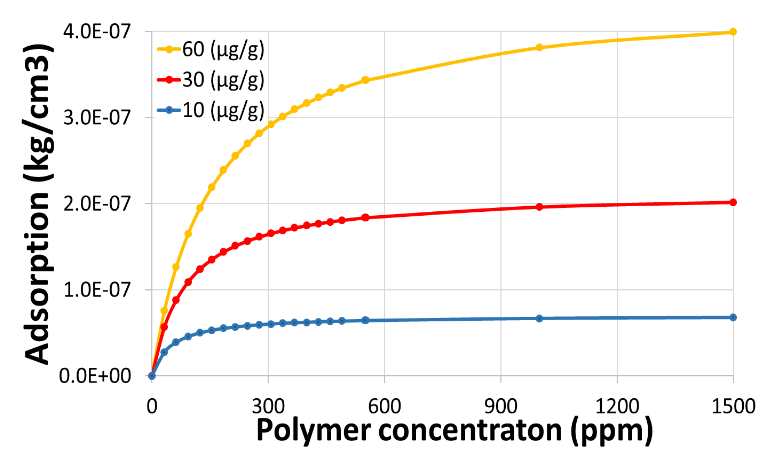

Figure 5. Adsorption curve - Langmuir.

multiplication variable to calculate the viscosity, taking into account the shear rate effect to model polymer viscosity dependence on concentration.

To include the non-Newtonian behavior, we implemented the viscosity data measured as a function of the shear rate in the simulation file. Figure 4 shows the rheological study from the lab including the non-Newtonian data (shear thinning effect) for $1250 \mathrm{ppm}$ of partially hydrolyzed polyacrylamide solution containing salt (Silveira et al., 2016).

The Base model considers a heavy oil with 180 CP viscosity, and connate water viscosity of $1.2 \mathrm{cP}$. We carried out the flow in one dimension and adopted relative permeability curves in the model with residual water saturation of $5 \%$ and residual oil saturation of $25 \%$. Equations 1 and 2 show the Corey model.

$k_{r w}\left(S_{w}\right)=0.6\left(\frac{S_{w}-0.05}{1-0.05-0.25}\right)^{2.5}$

$k_{r o}\left(S_{w}\right)=1.0\left(\frac{1-0.25-S_{w}}{1-0.05-0.25}\right)^{4.0}$

We defined a stop criterion for all simulated cases with $95 \%$ of water cut.

The sensitivity analysis developed aims at determining the effects of the adsorption, the accessible pore volume, the residual resistance factor, and the polymer concentration in the model results. The modeling analyses were developed, evaluating each parameter individually, as explained below.

Adsorption: Considering the maximum adsorption values and respective uncertainty reported in the literature (Table 1 ), we performed the SA for 10 $\mu \mathrm{g} / \mathrm{g}, 30 \mu \mathrm{g} / \mathrm{g}$ (P_Base), and $60 \mu \mathrm{g} / \mathrm{g}$ of maximum adsorption (ADS $S_{\max }$ ), as shown in Figure 5.

The equations below convert $\mu \mathrm{g} / \mathrm{g}$ to $\mathrm{kg} / \mathrm{cm}^{3}$. We used sandstone rock density $\left(\rho_{s}=2.65 \mathrm{~g} / \mathrm{cm}^{3}\right)$ and the porosity value $(\phi=28 \%)$ for the models.

$A D S_{\text {Max }}[\mu \mathrm{g} / \mathrm{g}] x$ Factor $=A D S_{\text {Max }}\left[\mathrm{kg} / \mathrm{cm}^{3}\right]$

Factor $=\frac{\rho_{s}(1-\phi)}{\phi} 10^{-9}$

Accessible Pore Volume: The APV for the Base Model (P_Base) was defined as $85 \%$. We also evaluated the SA considering the limit values $15 \%$ higher or lower than $85 \%$, based on literature data (Table 2).

Residual Resistance Factor: We evaluated three values of RRF, 1.0 (no resistance effect), 2.62 (Base Model), based on Zampieri (2012), and the highest value of 4.0, based on Delamaide (2014). 
Concentration: We set the Base Model (P_Base) as $1250 \mathrm{ppm}$ of the polymer concentration required to reach the target viscosity of $10 \mathrm{CP}\left(\right.$ at $\left.7,481 \mathrm{~s}^{-1}\right)$. The SA for the injected polymer concentration were $1000 \mathrm{ppm}$ and $1500 \mathrm{ppm}$, corresponding to the reference viscosity values of 7.6 and 13, respectively.

The proposed methodology aims to investigate the impacts of the above mentioned uncertain physical phenomena related to polymer flooding affect on oil recovery into porous media. Each of the mentioned parameters allows gathering information that, combined appropriately, can lead to a representative model for evaluating the polymer method.

\section{RESULTS}

This paper presents the sensitivity analysis for the core-scale model, seeking to evaluate the magnitude effect of different values of adsorption, accessible pore volume, residual resistance factor, and polymer concentration on displacement results. We compared each result obtained to the corresponding results obtained for water injection.

We obtained the following results for each case: (1) histories for water cut, cumulative water-oil ratio, average pressure and oil recovery; (2) profiles of water saturation, water viscosity, and water mobility at $11 \%$ and $42 \%$ of PV; (3) values of the cumulative produced water per cumulative produced oil ( $\mathrm{Wp} / \mathrm{Np})$, cumulative injected water per cumulative produced oil (Wi/Np), total injected pore volume (Total PV), water and polymer breakthrough times (Bt) and total duration of the injection phase, mass of polymer injected per cumulative produced oil $\left(\left(\mathrm{P}_{\text {mass }}\right)_{\mathrm{i}} / \mathrm{Np}\right)$ and recovery factor (RF).

One can notice from the results that the polymer flooding forms two self-sharpening saturation fronts. These fronts correspond to the arrival of water and polymer banks. The injected polymer solution displaces connate water and oil to the producer. Discussions related to these phenomena can be found in Pope (1980), Sorbie (1991), Al-sofi and Blunt, (2010), and Rios and Moreno (2014).

\subsection{Adsorption analysis}

Here, we present and discuss the effects of ADS on polymer flooding. Figure $6($ a) to (d) show that all responses reached, approximately, the same final value for all adsorption levels. Adsorption interferes more in the polymer advance front before its breakthrough. Polymer breakthrough is delayed until the reservoir layer achieves the maximum adsorption level.

From the water cut and the cumulative WOR curves, Figure $6(a)$ and (b), one can see that the higher the adsorption rate is, the faster the water production will be. This occurs due to the stripping of the polymer from the solution causing a polymer viscosity reduction along the flow. Consequently, the connate water breakthrough is anticipated and the polymer front is delayed.

Figure $6(c)$ shows that the average pressure history is inversely proportional to the adsorption level until the polymer BT, due to the initial loss of the injected polymer solution viscosity. Before the polymer breakthrough, lower adsorption ensures better maintenance of reservoir pressure. After that, all models examined reach the same pressure level.

After the delayed polymer front ( $P_{-}$ADS60) achieves the producer well, all cases reach almost the same oil recovery (Figure6(d)). The consequence is a delay in oil production, showing the importance of adsorption minimization.

Figure 6(e) to (j) shows profiles for water saturation, water phase viscosity and water phase mobility at $11 \%$ of the injected pore volume (before the water breakthrough, $28 \mathrm{~min}$ after the injection starts) and at $42 \%$ of injected pore volume (before the polymer breakthrough, $99 \mathrm{~min}$ after the injection starts).

Polymer adsorption effect tends to remove the polymer molecule from the solution. This phenomenon increases and accelerates the pushed connate water saturation, as evidenced in Figure6(e). This initial polymer retention in the rock decreases polymer solution viscosity (Figure 6(g)), reducing mobility control (Figure 6(i)). 


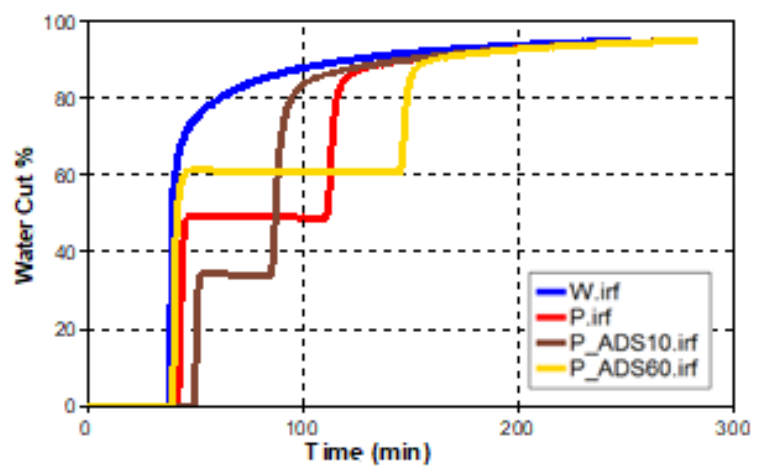

(a) Water cut

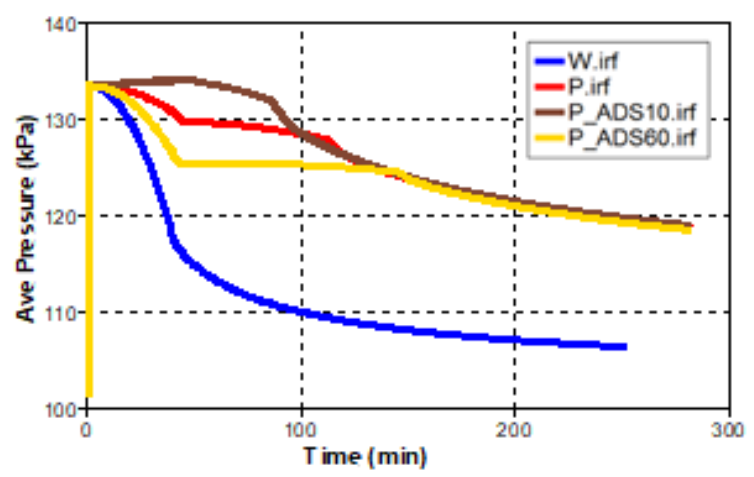

(c) A verage Pressure

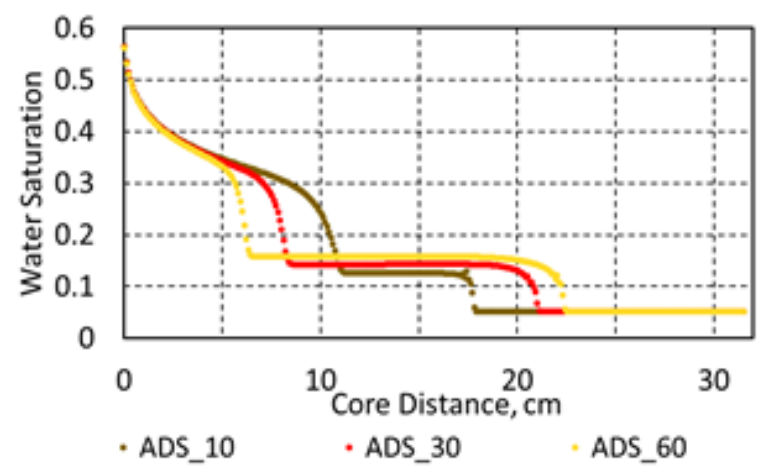

(e) Water Saturation Profile at $\mathbf{2 8} \mathrm{m}$ in

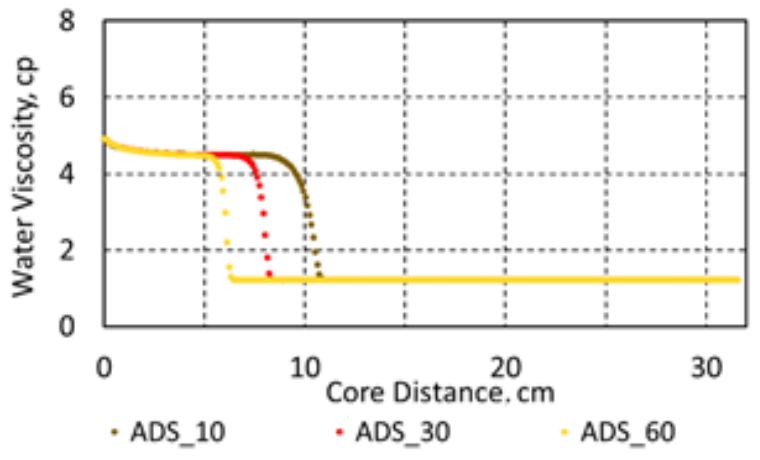

(g) Water Viscosity Profile at $28 \mathrm{~min}$

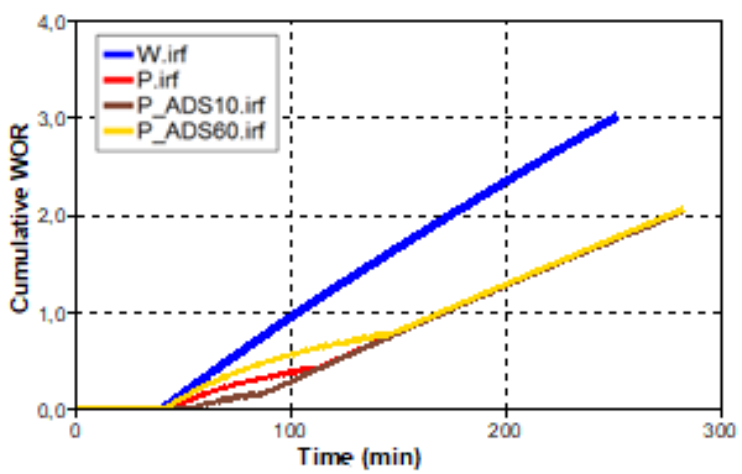

(b) Cum ulative WOR

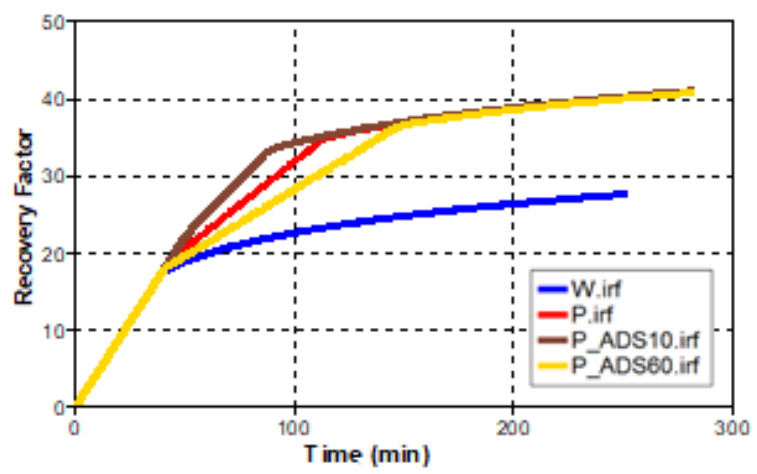

(d) Oil Recovery

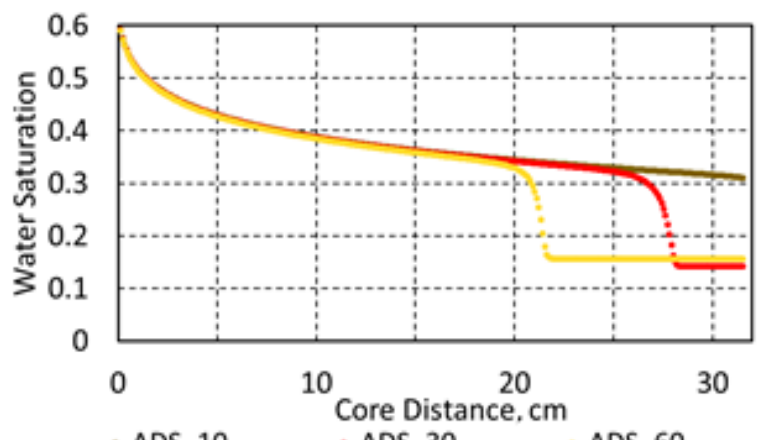

- ADS_10 ADS_30 ADS_60

(f) Water Saturation Profile at $99 \mathrm{~m}$ in

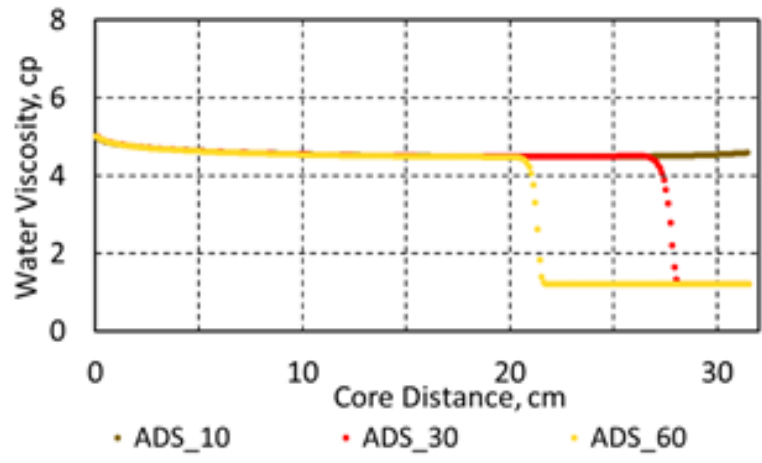

(h) Water Viscosity Profile at $99 \mathrm{~min}$

Figure 6. ADS analysis. 


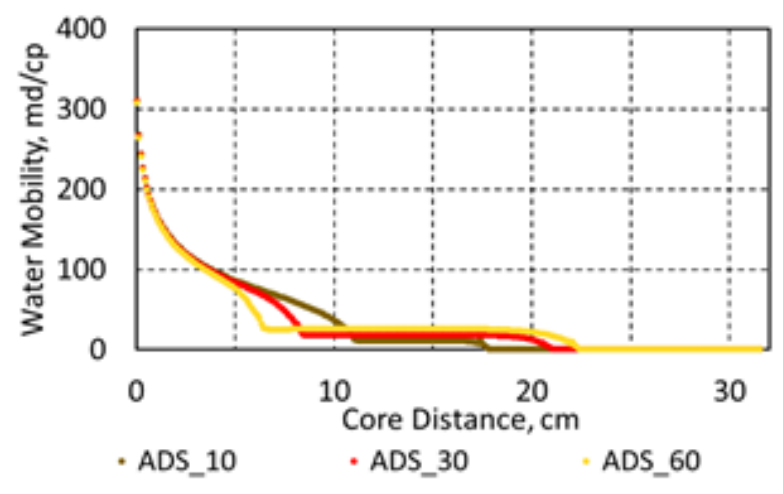

(i) Water Mobility Profile at $\mathbf{2 8} \mathrm{m}$ in

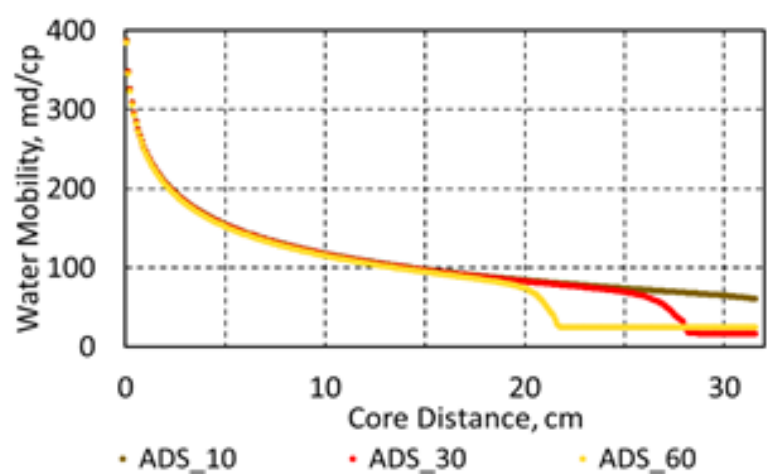

(j) Water Mobility Profile at $99 \mathrm{~m}$ in

Figure 6. ADS analysis (Cont.)

Table 4 summarizes the quantitative results and shows the values at the stopping time $(95 \%$ of the water cut).

The higher the adsorption is, the higher the ratio of injected and produced water per oil produced will be. The connate water breakthrough is anticipated, and the polymer front breakthrough is delayed. As a result, the ratio of the mass of polymer used per oil produced increases. The total injected pore volume and the recovery factor were quite similar for the studied cases. Ferreira (2019) reported experimental and field-scale simulation studies regarding retention, and our findings are aligned with those results and with the one found in classical literature, as presented in the introduction of this work.

\subsection{Accessible Pore Volume analysis}

We evaluate the accessible pore volume (APV) in this section. With the goal of comparing different values of APV, we set the base model $(P)$ at $85 \%$

Table 4. Results of sensitivity analysis of ADS.

\begin{tabular}{lccc}
\hline \multicolumn{1}{c}{ Parameter } & P_ADS10 & P_Base & P_ADS60 \\
\hline Adsorption $(\boldsymbol{\mu g} / \mathrm{g})$ & $\mathbf{1 0}$ & $\mathbf{3 0}$ & $\mathbf{6 0}$ \\
\hline Wp/Np & 2.038 & 2.055 & 2.067 \\
Wi/Np & 3.037 & 3.054 & 3.067 \\
Total PV & 1.185 & 1.189 & 1.189 \\
Water Bt [min] & 49.76 & 41.76 & 39.57 \\
Polymer Bt [min] & 83.76 & 107.76 & 140.76 \\
End-time [min] & 281.87 & 282.90 & 282.88 \\
(Pmass)i/Np [kg/m ${ }^{3}$ ] & 4.100 & 4.123 & 4.140 \\
RF [\%] & 41.08 & 41.00 & 40.83 \\
\hline \hline
\end{tabular}

and the variation range of $\pm 15 \%, 100 \%$, and $70 \%$, respectively.

From the water cut and the cumulative WOR (Figure $7(a)$ and (b), respectively), one can observe that the smaller the accessible pore volume is, the lower produced water volumes and the faster polymer breakthrough will be. Polymer solution flows only through the accessible portion maintaining the average pressure of the porous media Figure $7(\mathrm{c})$ ) and anticipating oil production (Figure $7(d)$ ).

Figure 7 (e) to (j) shows water saturation, water phase viscosity, and water phase mobility profiles at $11 \%$ and $42 \%$ of the total PV injected. It is possible to observe that these parameters were affected slightly by the accessible pore volume, mainly in the polymer advance front.

Table 5 shows the results of APV analysis - 70\%, $85 \%$ (Base Model) and $100 \%$ - for the Wp/Np, $\mathrm{Wi} / \mathrm{Np}$, total injected PV, breakthrough and end time, mass of injected polymer per recovered oil, and recovery factor.

The responses evaluated were not strongly affected at the end of each simulation. Lamas et al. (2016) studied this parameter in a field-scale model and showed the influence on the economic aspect of a polymer flooding project. Their remarks are aligned with the outcomes observed by our group. The ratio of injected and produced water per produced oil decreases for lower values of APV, which means that one needs to inject and produce less water to recover the mobile oil. The end time and the polymer breakthrough time are delayed as a consequence of higher APV to the polymer flooding. 


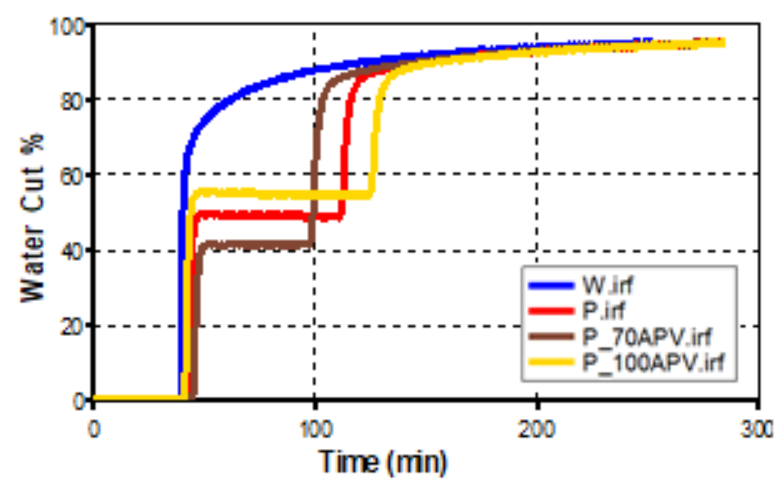

(a) Water cut

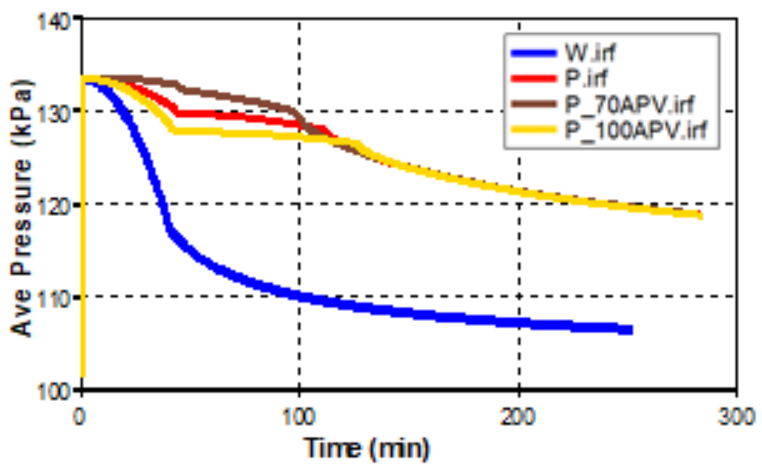

(c) A verage Pressure

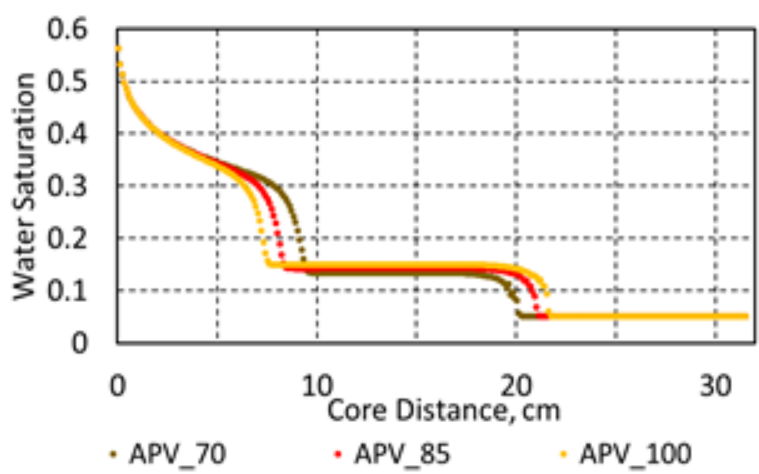

(e) Water Saturation Profile at $28 \mathrm{~m}$ in

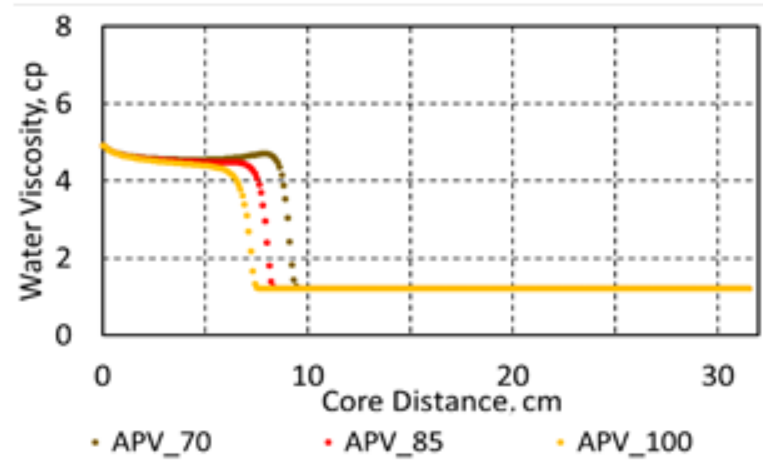

(g) Water Viscosity Profile at $28 \mathrm{~min}$

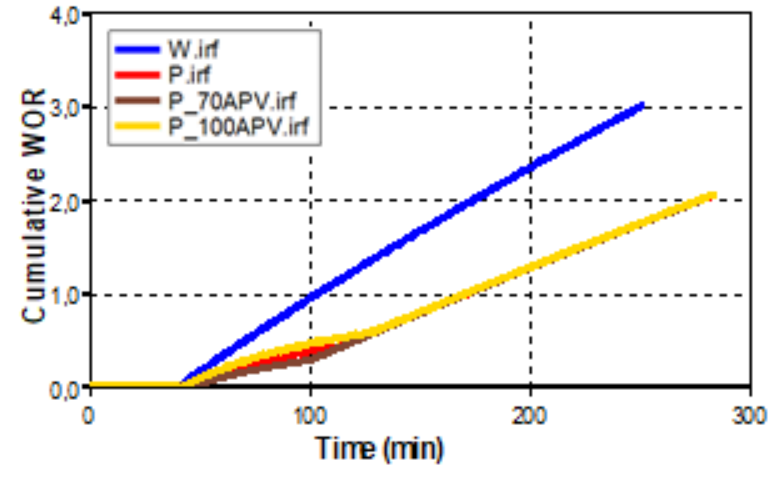

(b) Cum ulative WOR

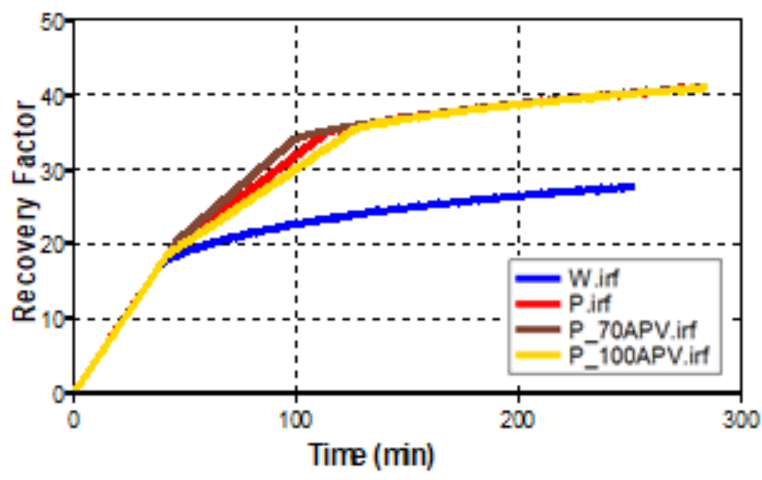

(d) Oil Recovery

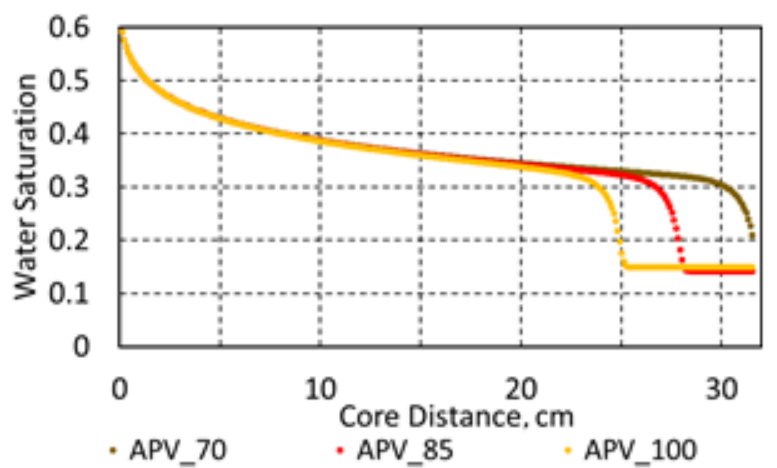

(f) Water Saturation Profile at $99 \mathrm{~m}$ in

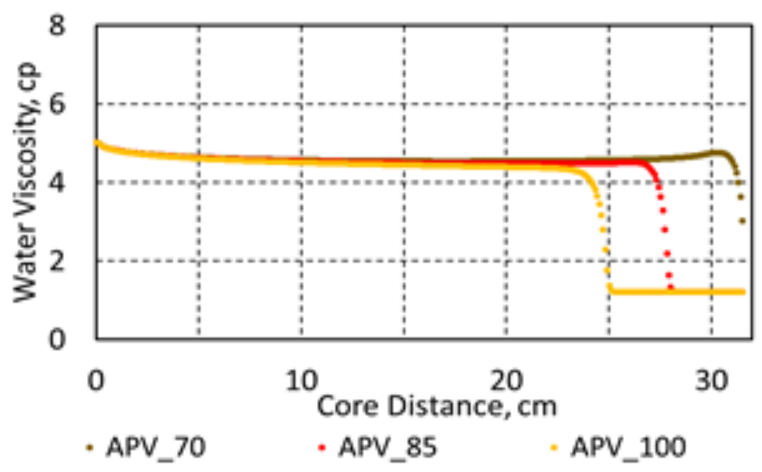

(h) Water Viscosity Profile at $99 \mathrm{~min}$

Figure 7. APV Analysis. 


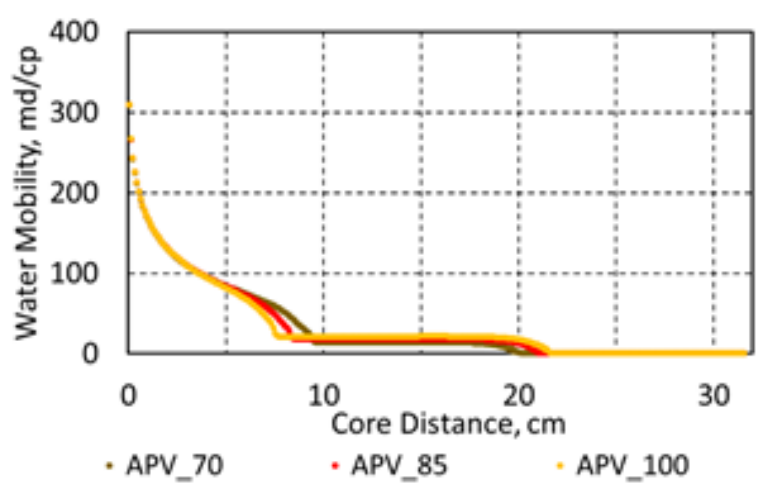

(i) Water Mobility Profile at $\mathbf{2 8} \mathrm{m}$ in

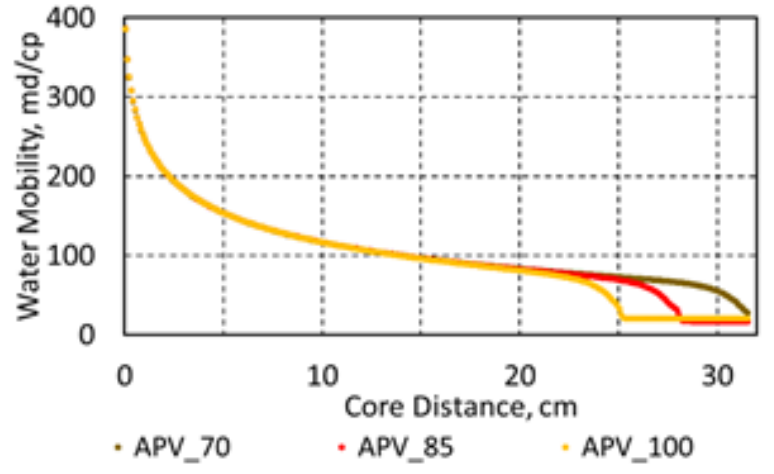

(j) Water Mobility Profile at $99 \mathrm{~m}$ in

Figure 7. APV Analysis (Cont.)

\subsection{Residual Resistance Factor analysis}

The sensitivity analysis of the residual resistance factor presents three different values of RRF - 1.0 (no resistance effect), 2.62 (Base Model), and 4.0 (high resistance).

As observed in Figure 8(a) and (b), as RRF increases, water cut delays and cumulative WOR decreases. The higher the average pressure is, the higher the RRF (Figure 8(c)) will be, for a constant flow rate. Figure $8 d$ shows the recovery factor behavior when the RRF changes. Higher values of RRF anticipate oil recovery as well as improve the final recovery factor.

Figure $8(e)$ to (j) show the profiles of water saturation, water viscosity, and water mobility. As observed, an increase in the RRF delays connate water and polymer advance front leading to viscosity increase and permeability reduction. This mobility reduction suppresses the formation of possible viscous fingers along the porous media, improving the areal sweep. The water-phase mobility stays low for high RRF until polymer breakthrough. Then, it increases after sweeping the reservoir oil efficiently.

The results determined at $95 \%$ of the water cut considering three different values of RRF are summarized in Table 6, quantifying the discussed trend.

Analyzing the results, we can observe a positive correlation between RRF and oil recovery. In this case, we can point out a tendency of reduction for both injected and produced water per produced oil. Higher RRF delays the water breakthrough, increasing the average pressure. The results observed are in accordance with what is stated in the literature (Shi et al., 2010; Zampieri, 2012; Silveira et al., 2018). Observing the plots over distance makes the understanding clearer, accounting for inherent uncertainties under laboratory when performing a core-flooding experiment.

Table 5. Results of sensitivity analysis of APV.

\begin{tabular}{lccc}
\hline \hline \multicolumn{1}{c}{ Parameter } & P_APV70 & P_Base & P_APV100 \\
\hline APV level & 70 & 85 & 100 \\
\hline Wp/Np & 2.034 & 2.055 & 2.076 \\
Wi/Np & 3.033 & 3.054 & 3.076 \\
Total PV & 1.181 & 1.189 & 1.198 \\
Water Bt [min] & 43.86 & 41.76 & 40.86 \\
Polymer Bt [min] & 94.86 & 107.76 & 120.86 \\
End-time [min] & 281.00 & 282.90 & 284.86 \\
(Pmass)i/Np [kg/m $\left.{ }^{3}\right]$ & 4.095 & 4.123 & 4.153 \\
RF [\%] & 41.01 & 41.00 & 40.99 \\
\hline \hline
\end{tabular}

Table 6. Results of sensitivity analysis of RRF.

\begin{tabular}{lccc}
\hline \multicolumn{1}{c}{ Parameter } & P_RRF1.0 & P_Base & P_RRF4.0 \\
\hline RRF level & $\mathbf{1}$ & $\mathbf{2 . 6 2}$ & $\mathbf{4}$ \\
\hline Wp/Np & 2.514 & 2.055 & 1.850 \\
Wi/Np & 3.514 & 3.054 & 2.849 \\
Total PV & 1.185 & 1.189 & 1.173 \\
Water Bt [min] & 39.57 & 41.76 & 42.76 \\
Polymer Bt [min] & 96.76 & 107.76 & 111.76 \\
End-time [min] & 281.76 & 282.90 & 279.00 \\
(Pmass)i/Np [kg/m ${ }^{3}$ ] & 4.744 & 4.123 & 3.847 \\
RF [\%] & 35.49 & 41.00 & 43.34 \\
& & & \\
\hline \hline
\end{tabular}




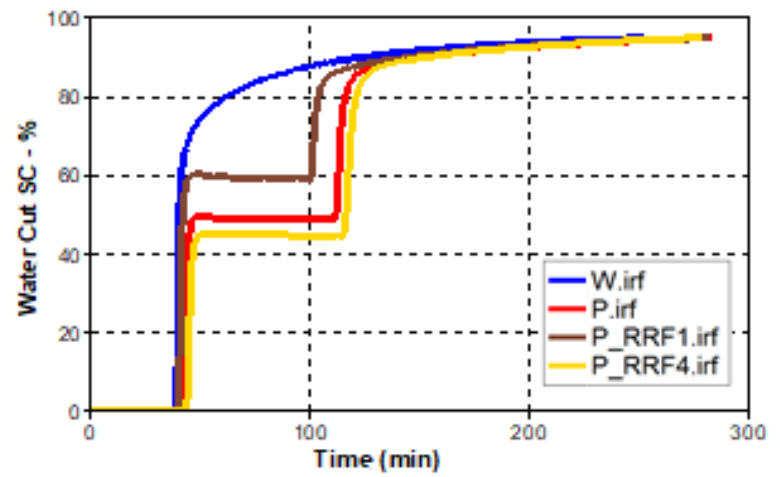

(a) Water cut

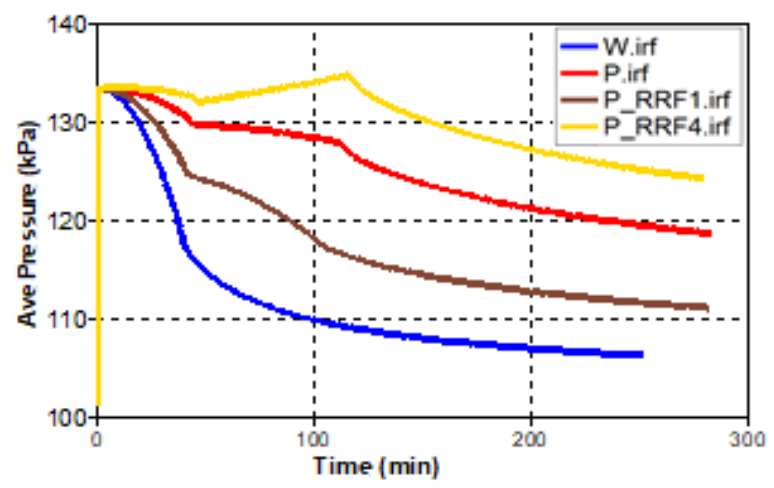

(c) A verage Pressure

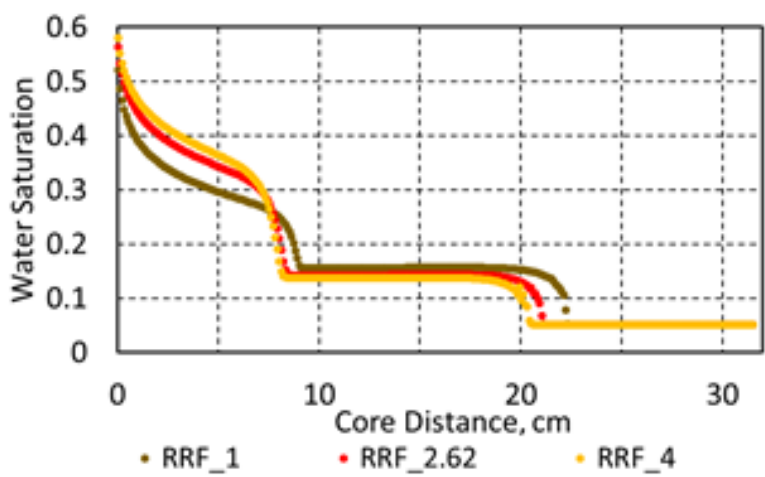

(e) Water Saturation Profile at $\mathbf{2 8} \mathrm{m}$ in

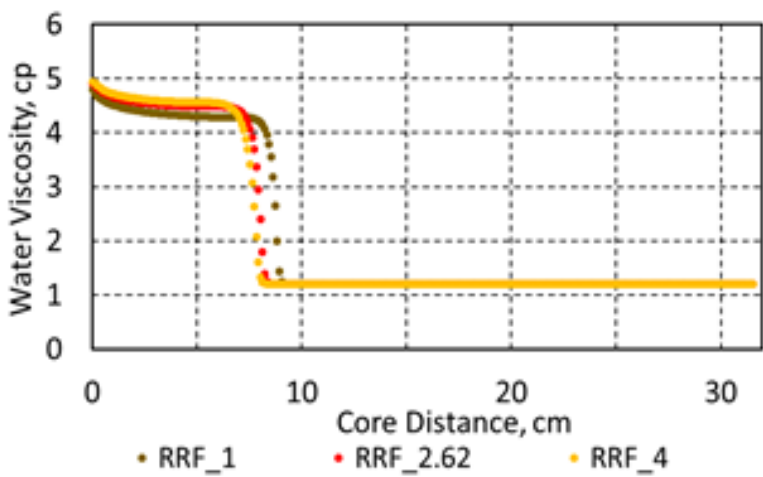

(g) Water Viscosity Profile at $\mathbf{2 8} \mathrm{min}$

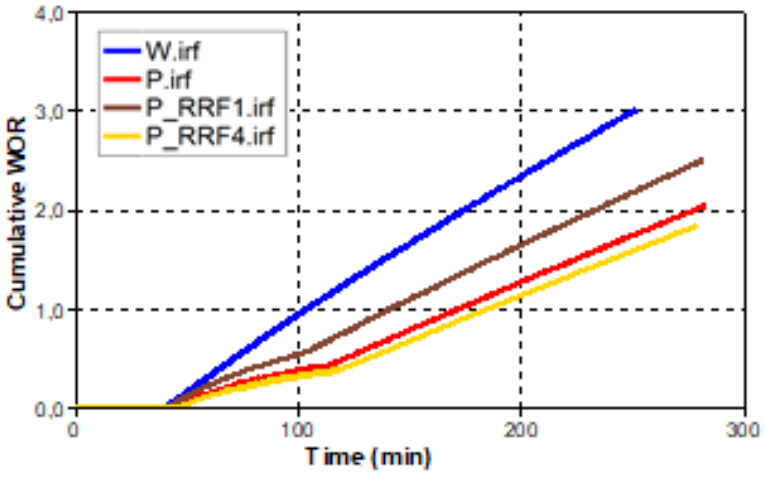

(b) Cum ulative WOR

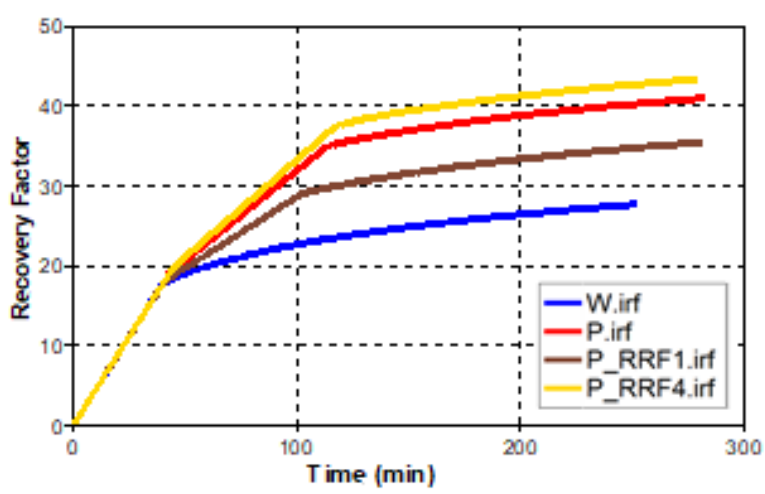

(d) Oil Recovery

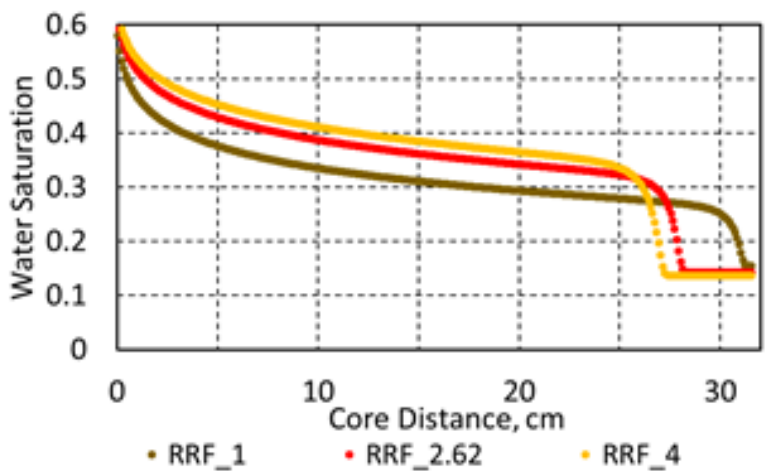

(f) Water Saturation Profile at $99 \mathrm{~m}$ in

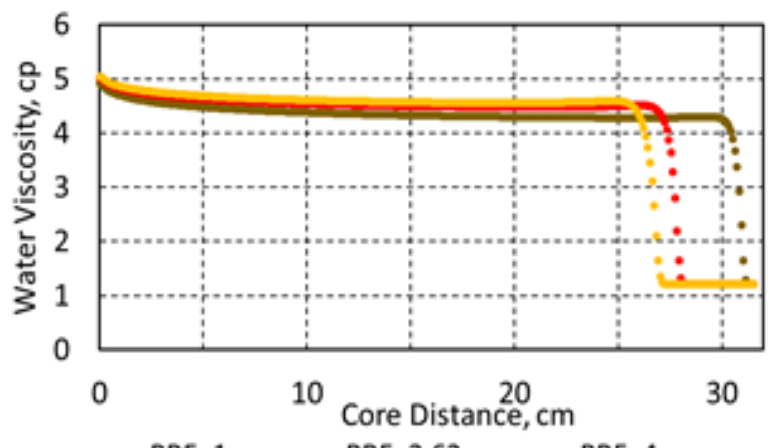

- RRF_1 - RRF_2.62 - RRF_4

(h) Water Viscosity Profile at 99 min

Figure 8. RFF Analysis. 


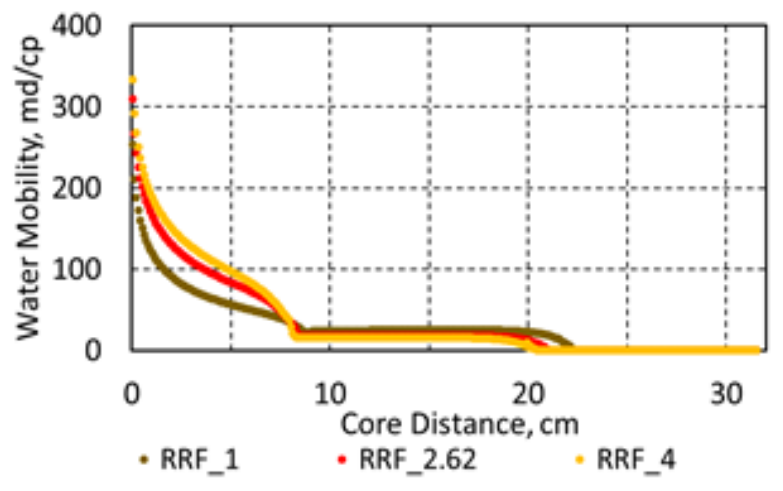

(i) Water Mobility Profile at 28 min

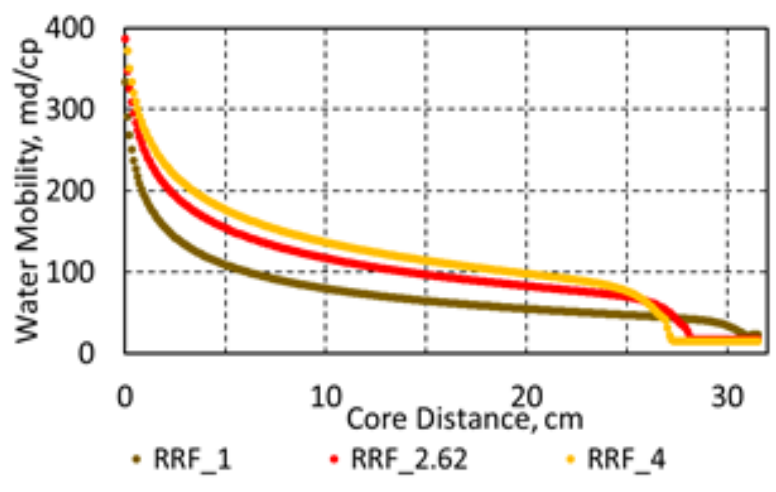

(j) Water Mobility Profile at $99 \mathrm{~m}$ in

Figure 8. RFF Analysis (Cont.)

\subsection{Concentration analysis}

Figure $9(\mathrm{a})$ to (d) shows the sequence of plots for $1000 \mathrm{ppm}$, for $1250 \mathrm{ppm}$ (P_Base), and 1500 ppm of polymer injection and water injection.

A direct consequence of the increase in polymer injection concentration is the increase in solution viscosity. The higher viscosity of the injected fluid improves displacement efficiency since mobility ratio is reduced. We can note the benefits of higher polymer concentrations in Figure 9 (a) and (b), which shows the reduced water production over time. Figure 9(c) shows that the higher the polymer concentration is, the higher the average pressure in the reservoir will be. High pressures may fracture the rock when reaching its critical values (rupture pressure). The recovery factor improved as the polymer concentration increased Figure 9d).

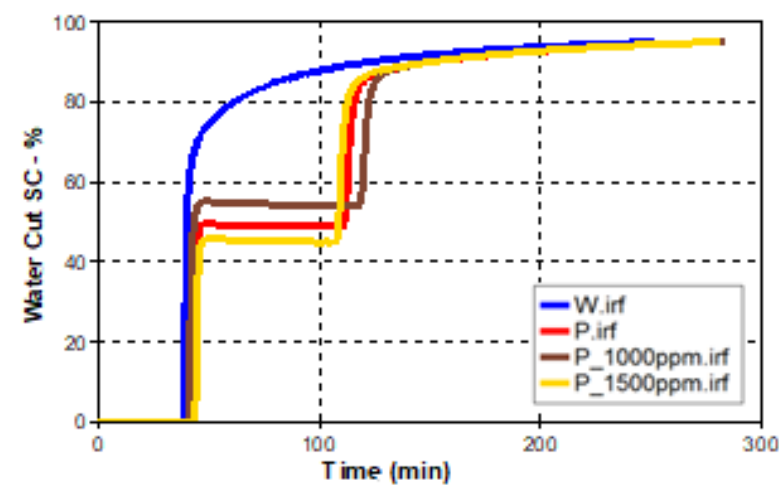

(a) Water cut

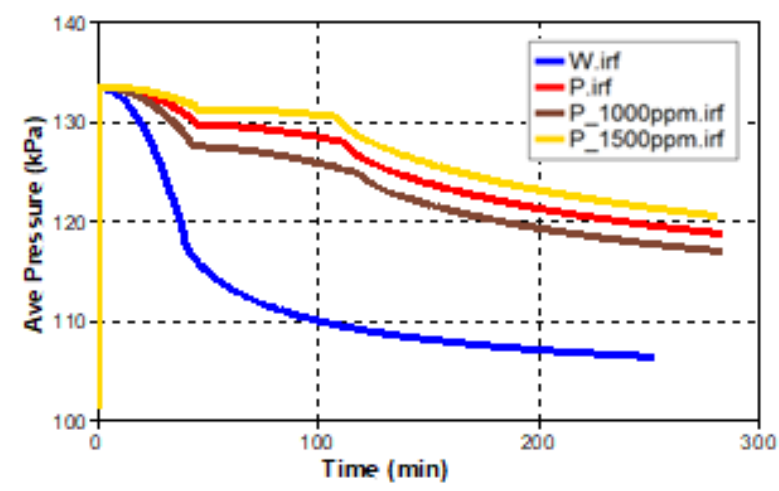

(c) A verage Pressure

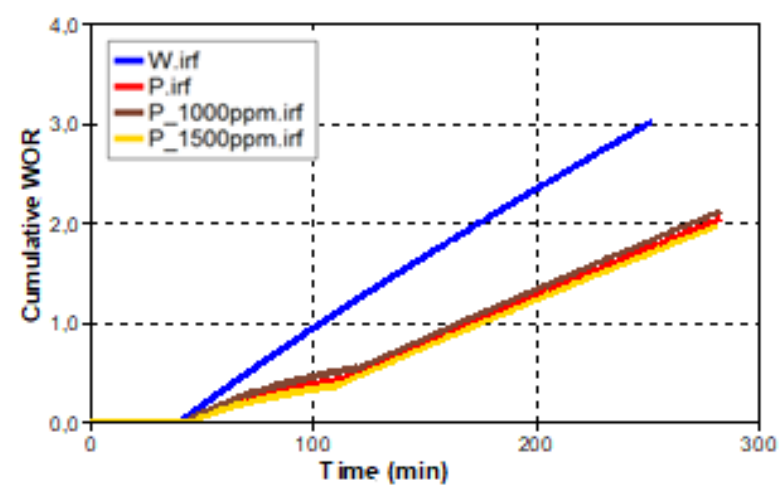

(b) Cum ulative WOR

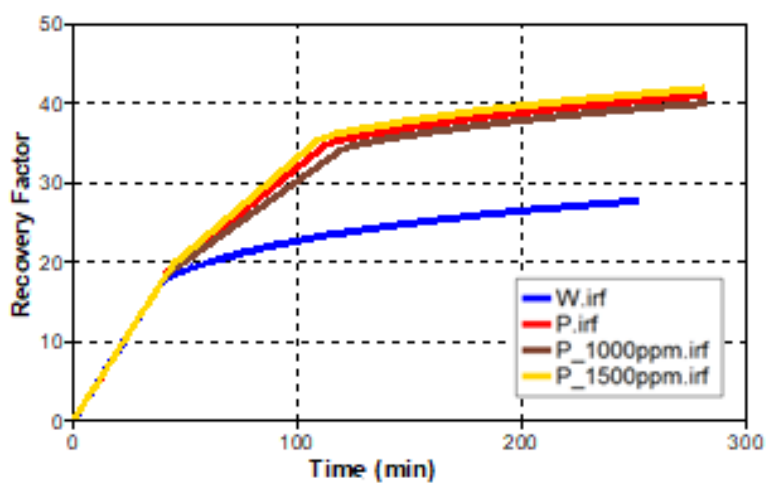

(d) Oil Recovery

Figure 9. CCP Analysis. 


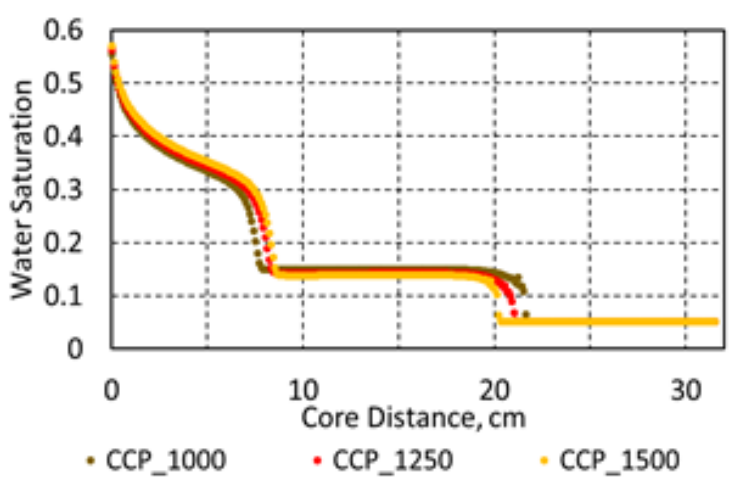

(e) Water Saturation Profile at $28 \mathrm{~m}$ in

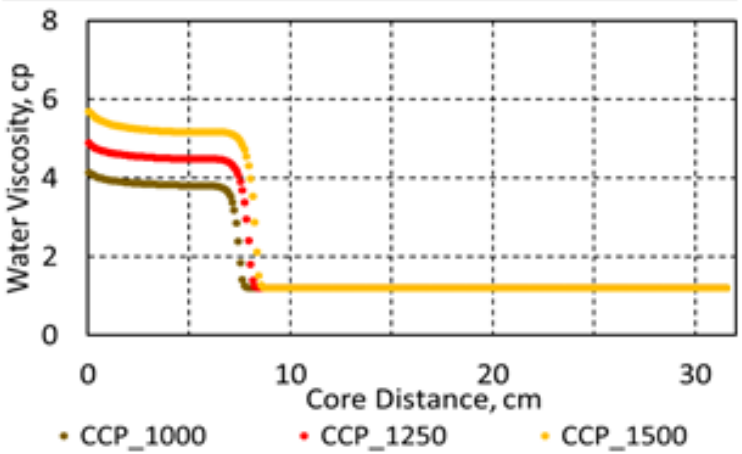

(g) Water Viscosity Profile at $\mathbf{2 8} \mathrm{m}$ in

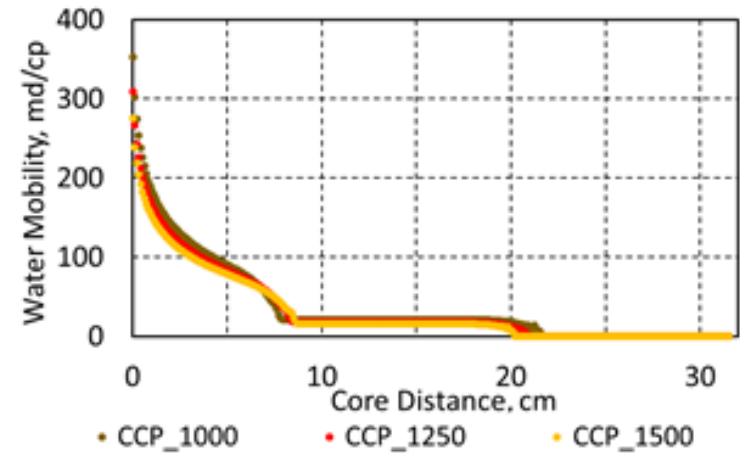

(i) Water Mobility Profile at $\mathbf{2 8} \mathrm{m}$ in

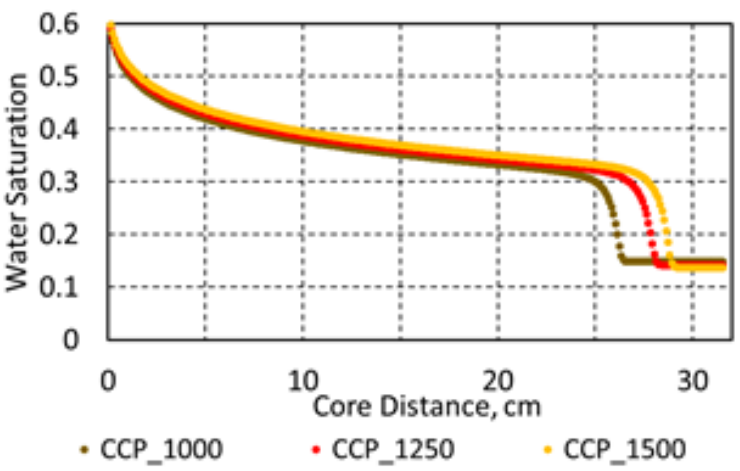

(f) Water Saturation Profile at $99 \mathrm{~m}$ in

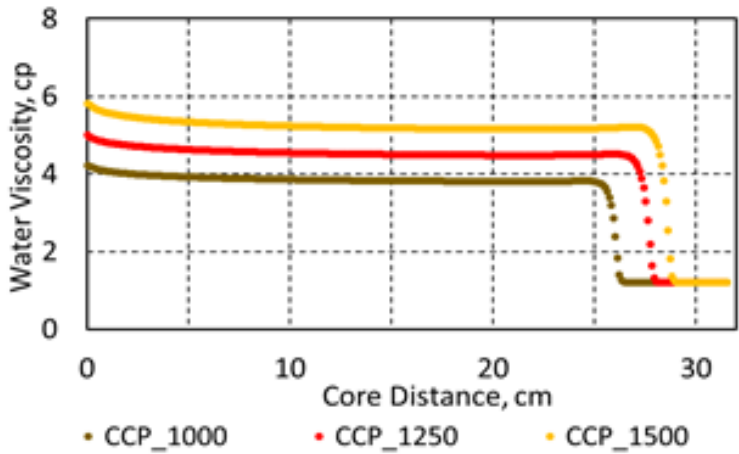

(h) Water Viscosity Profile at $\mathbf{9 9} \mathbf{m i n}$

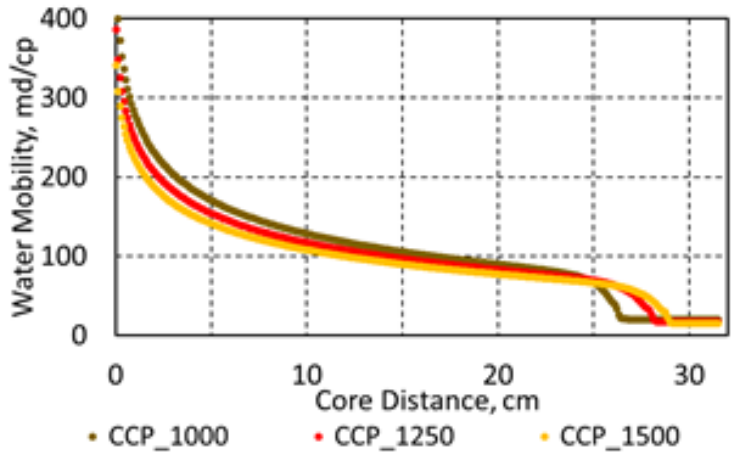

(j) Water Mobility Profile at $\mathbf{9 9} \mathrm{m}$ in

Figure 9. CCP analysis (Cont.)

Additionally, higher CCP leads to a delay in connate waterfront, and an acceleration of polymer BT (Figure 9(e) and (f)). One can see that water mobility is reduced (Figure $9(\mathrm{i}$ )and (j)) as viscosity increases (Figure $9 \mathrm{~g}$ and $\mathrm{h}$ ). Polymer concentration remarks agree with the polymer applications addressed in the introduction section. The present analysis can assist in producing data of history matching or in forecasting two-phase polymer-flooding lab tests, due to the importance of compression of water and polymer bank displacement and dispersion into porous media.

Table 7 summarizes polymer flooding trends of all three models with different polymer solution concentrations injected.

For higher values of CCP, quantitative advantages, such as the improved oil recovery and the delayed water breakthrough time, can be seen in Table 6. However, we observe an increase in the polymer mass used in the oil recovery (Polymer mass) i/Np.

Since high polymer concentrations can be costly, it is essential to observe the limit of the injected solution. Depending on the oil and polymer prices, it may not be economically attractive to inject concentrated polymer solutions. 
Table 7. Results of sensitivity analysis of CCP.

\begin{tabular}{lccc}
\hline \multicolumn{1}{c}{ Parameter } & P_CCP1000 & P_Base & P_CCP1500 \\
\hline CCP & 1000 & 1250 & 1500 \\
\hline Wp/Np & 2.130 & 2.055 & 1.975 \\
Wi/Np & 3.130 & 3.054 & 2.974 \\
Total PV & 1.189 & 1.189 & 1.181 \\
Water Bt [min] & 40.66 & 41.76 & 43.76 \\
Polymer Bt [min] & 115.72 & 107.76 & 105.72 \\
End-time [min] & 282.84 & 282.90 & 280.84 \\
(Pmass)i/Np [kg/m ${ }^{3}$ ] & 3.380 & 4.123 & 4.818 \\
RF [\%] & 40.00 & 41.00 & 41.79 \\
\hline \hline
\end{tabular}

\section{CONCLUSIONS}

The results presented in this work allow us to understand the effects of rock-fluid interaction. Since oil recovery mechanisms and many aspects of the polymer solution flow in porous media are yet to be understood, this may raise challenging technical issues.

Sensitivity analysis results show that the adsorption does not change the final results. However, before the polymer breakthrough, an increase in the amount of adsorption level strips polymer from the advance front. As a consequence, water production increases, and the polymer breakthrough delays, thus, retarding oil recovery. The average pressure is low for high levels of adsorption.

It is noteworthy that, in a field project, a high concentration of polymer solution is not guaranteed or may also not inject a large pore volume of the polymer solution. In such cases, adsorption becomes the dominant factor that may decide the economics of a polymer flooding project.

The accessible pore volume proved to have a low impact on the observed responses. We observed the differences among models' results before polymer breakthrough. Low values of accessible pore volume lead to low cumulative water-oil ratio, fast polymer breakthrough, and oil recovery anticipation. Also, the average pressure is higher. In all models, after the polymer front achieves the producer well, the results tend to stabilize at the same level for different values of accessible pore volume.
The residual Resistance Factor plays an important role in oil recovery by polymer flooding. High Residual Resistance Factor values correspond to low water cut and reduced cumulative WOR. Moreover, higher levels of Residual Resistance Factor contribute to high average pressure, anticipating the oil recovery and improving the final recovery factor.

An increase in the polymer injection concentration will increase the solution's viscosity. Higher injection fluid viscosity promotes a better displacement efficiency since the mobility ratio is reduced. Consequently, less injected water is necessary to produce oil and less water is produced over the time. Therefore, oil recovery is anticipated, and recovery factor is improved. The higher the polymer concentration is, the higher the average pressure in the reservoir will be.

\section{ACKNOWLEDGMENTS}

The authors would like to thank Computer Modeling Group (CMG), Brazilian National Agency of Petroleum Natural Gas and Biofuels (ANP), Equinor, and CAPES for supporting this research.

\section{REFERENCES}

Al-Sofi, A. M.; Blunt, M. J. Control of numerical dispersion in simulations of augmented waterflooding. SPE Improved Oil Recovery Symposium, SPE 129658-MS, 24-28 April, Tulsa, Oklahoma, USA, January 1, 2010. https://doi.org/10.2118/129658-MS

Aluhwal, O. K. H. Simulation study of improving oil recovery by polymer flooding in a Malaysian reservoir. Master's thesis, Universiti Teknologi Malaysia, Faculty of Chemical and Natural Resources Engineering, 2008.

Carcoana, A. Applied Enhanced Oil Recovery, Library of Congress Cataloging Publication Data. Prentice Hall, Inc, New Jersey, EUA, 1992.

Choi, S. K. $p \mathrm{H}$ sensitive polymers for novel conformance control and polymer flooding applications. Doctoral Thesis, The University of Texas at Austin, 2008. 
Dawson, R.; Lantz, R. B. Inaccessible pore volume in polymer flooding. Society of Petroleum Engineers Journal, v. 12(5), SPE-3522-PA, October 1, 1972. https://doi.org/10.2118/3522-PA

De Bons, F.E.; Braun, R.W. Polymer flooding: still viable IOR technique. European IOR Symposium, Vienna, Austria, 15-17 May, 1995.

Delamaide, E. Polymer flooding of heavy oil From screening to full-field extension. Society of Petroleum Engineers. SPE Heavy and Extra Heavy Oil Conference, SPE-171105-MS, Medellín, Colombia 24-26 September 2014. https://doi.org/10.2118/171105-MS

Delamaide, E.; Zaitoun, A.; Renard, G.; Tabary, R. Pelican Lake Field: First successful application of polymer flooding in a heavy-oil reservoir. Society of Petroleum Engineers. SPE Enhanced Oil Recovery Conference, SPE-165234-MS, Kuala Lumpur, Malaysia, 2-4 July 2013.

https://doi.org/10.2118/165234-MS

Fabbri, C.; Romero, C.; Aubertin, F.; Nguyen, M.; Hourcq, S.; Hamon, G. Secondary polymer flooding in extra-heavy oil: Gaining information on polymeroil relative permeabilities. SPE Enhanced Oil Recovery Conference, Kuala Lumpur, Malaysia, 2-4 July 2013. https://doi.org/10.2118/165237-MS

Ferreira, V. H. S. Injection scheme to reduce retention and improve economics of polymer enhanced oil recovery. Society of Petroleum Engineers. SPE Annual Technical Conference and Exhibition, SPE-199771-STU, Calgary, Alberta, Canada, 30 September - 2 October 2019. https://doi.org/10.2118/199771-STU

Grattoni, B. C. A.; Luckham, P. F.; Jing, X. D.; Norman, L.; Zimmerman, R. W. Polymers as relative permeability modifiers: adsorption and the dynamic formation of thick polyacrylamide layers. Journal of Petroleum Science and Engineering, v. 45(3-4), p. 233-245, 2004.

https://doi.org/10.1016/i.petrol.2004.07.002

Hatzignatiou, D. G.; Moradi, H.; Stavland, A. Experimental investigation of polymer flow through water- and oil-wet Berea Sandstone core samples. Society of Petroleum Engineers., EAGE Annual Conference \& Exhibition incorporating SPE Europec, SPE-164844-MS, London, UK, 10-13 June 2013a. https://doi.org/10.2118/164844-MS
Hatzignatiou, D. G.; Norris, U. L.; Stavland, A. Core-scale simulation of polymer flow through porous media. Journal of Petroleum Science and Engineering, v. 108, p. 137-150, 2013b.

https://doi.org/10.1016/i.petrol.2013.01.001

Jamaloei, B.; Kharrat, R.; Torabi, F. A mechanistic analysis of viscous fingering in lowtension polymer flooding in heavy-oil reservoirs. SPE Latin American \& Caribbean Petroleum Engineering Conference, SPE 138127, Lima, Peru, 1-3 December 2010. https://doi.org/10.2118/138127$\underline{\mathrm{MS}}$

Jennings, H. Y.; Rogers, J. H.; West, T. J. Factors influencing mobility control by polymer solutions. SPE 2867. Journal of Petroleum Technology, v. 23(3), p. 391-401, 1971.

https://doi.org/10.2118/2867-PA

Knight, B. L.; Jones, S. C.; Parsons, R. W. Discussion. SPE Journal, p. 643-644, 1974.

Lake, L. W. Enhanced Oil Recovery. Englewood Cliffs, New Jersey, Prentice Hall, 1989.

Lamas, L. F.; Schiozer, D. J.; Delshad, M. Impacts of polymer properties on field indicators of reservoir development projects Journal of Petroleum Science and Engineering, v. 147, p. 346355, 2016.

https://doi.org/10.1016/i.petrol.2016.05.020

Lei, Y.; Li, S; Zhang, X.; Zhang, Q.; Guo, L. Optimal control of polymer flooding based on maximum principle. Journal of Applied Mathematics, v. 2012, Article ID 987975, 2012. https://doi.org/10.1155/2012/987975

Lötsch, T.; Muller, T.; Pusch, G. The effect of inaccessible pore volume on polymer core experiments. SPE Oilfield and Geothermal Chemistry Symposium, SPE-13590-MS, Phoenix, Arizona, 10p, 9-11 March 1985.

https://doi.org/10.2118/13590-MS

Manichand, R. N.; Seright, R. S. Field vs laboratory polymer retention values for a polymer flood in the Tambaredjo Field. Society of Petroleum Engineers. SPE Improved Oil Recovery Symposium, SPE-169027-MS, Tulsa, Oklahoma, USA, 12-16 April 2014. https://doi.org/10.2118/169027-MS 
Melo, M. A. Simulação física e matemática do processo de recuperação de petróleo com fluidos de base polimérica. Tese de Doutorado. Universidade Federal do Rio de Janeiro - UFRJ, Instituto de Macromoléculas Professora Eloisa Mano - IMA, Rio de Janeiro, 2008. (in Portuguese)

Mohammadi, H. Mechanistic modeling, design, and optimization of alkaline/surfactant/ polymer flooding. Thesis (Doctorate). The University of Texas at Austin, 2008.

Osterloh, W. T.; Law, E. J. Polymer transport and rheological properties for polymer flooding in the North Sea Captain Field. SPE/DOE Improved Oil Recovery Symposium, Paper SPE 39694, Tulsa, OK, USA, 19-22 April 1998.

https://doi.org/10.2118/39694-MS

Pancharoen, M.; Thiele, M. R.; Kovscek, A. R. Inaccessible pore volume of associative polymer floods. SPE Improved Oil Recovery Symposium, Paper SPE 129910, Tulsa, OK, USA, 24-28 April 2010. https://doi.org/10.2118/129910-MS

Pope, G. A. The application of fractional flow theory to enhanced oil recovery. Society of Petroleum Engineers. Society of Petroleum Engineers Journal, v. 20(3), 1980.

https://doi.org/10.2118/7660-PA

Rios, V. S.; Moreno, R. B. Z. L. Sensitivity analysis of polymer flooding based on fractional flow model. Rio Oil \& Gas Expo and Conference, IBP2101_14, p. 1-8, Rio de Janeiro, Brasil, 15-18 September 2014.

Salazar, A. Y. Evaluation of alkaline-polymer formulations in Minnelusa reservoirs. Master of Science thesis. University of Wyoming, Department of Chemical \& Petroleum Engineering, May 2009.

Seright, R. Potential for polymer flooding reservoirs with viscous oils. Society of Petroleum Engineers. SPE Improved Oil Recovery Symposium, SPE-129899-MS, Tulsa, Oklahoma, USA, 24-28 April 2010. https://doi.org/10.2118/129899-MS

Sheng, J. J. Modern chemical enhanced oil recovery - Theory and practice. Elsevier, ISBN 9781-85617-745-0, 2011. https://doi.org/10.1016/B9781-85617-745-0.00001-2
Sheng, J. J. EOR field case studies. Gulf Professional Publishing, Boston, Pages 63-82, ISBN 9780123865458, 2013. https://doi.org/10.1016/B9780-12-386545-8.00003-8

Sheng, J. J.; Leonhardt, B.; Azri, N. Status of polymer-flooding technology. Society of Petroleum Engineers. Journal of Canadian Petroleum Technology, SPE-174541-PA, v. 54(2), 2015. https://doi.org/10.2118/174541-PA

Shi, L.; Ye, Z.; Zhang, Z.; Zhou, C.; Zhu, S.; Guo, Z. Necessity and feasibility of improving the residual resistance factor of polymer flooding in heavy oil reservoirs. Petroleum Science, v. 7, p. 251-256, 2010. https://doi.org/10.1007/s12182-010-0029-5

Silva, I. P. G.; Lucas, E. F.; Franca, F. P. Study of conditions for polyacrylamide use in petroleum reservoirs: physical flow simulation in porous media. Chemistry \& Chemical Technology, v. 4, p. 73-80, 2010. https://doi.org/10.23939/chcht04.01.073

Silveira, B. M. O.; LOPES, L. F.; MORENO, R. B. Z. L. Rheological Approach of HPAM solutions under harsh conditions for EOR applications. International Journal of Engineering \& Technology IJET-IJENS, v. 16(03), p. 1-8, 161403-2828-IJETIJENS, 2016.

Silveira, B. M. O.; LOPES, L. F.; MORENO, R. B. Z. L. Polymer flooding in a high salinity heavy-oil reservoir. Brazilian Journal of Petroleum and Gas, v. 12(1), p. 35-51, 2018.

https://doi.org/10.5419/bjpg2018-0004

Sorbie, K. S. Polymer-improved oil recovery, CRC Press, Inc., USA and Canada, 1991.

https://doi.org/10.1007/978-94-011-3044-8

Wang, J. Experimental and numerical study of enhanced heavy oil recovery by chemical flooding. Doctoral Thesis, University of Calgary, Department of Chemical and Petroleum Engineering, Calgary, Alberta, December, 2009.

Wang, J.; Dong, M. A Laboratory study of polymer flooding for improving heavy oil recovery. Petroleum Society of Canada. Canadian International Petroleum Conference, PETSOC2007-178, Calgary, Alberta, 12-14 June 2007. https://doi.org/10.2118/2007-178 
Willhite, G. P.; Dominguez, J. G., Mechanisms of polymer retention in porous media. In: Shah, D. O.; Schechter, R.S. (Eds.), Improved Oil Recovery by Surfactant and Polymer Flooding. Academic Press, New York, NY, p. 511-554, 1977.

https://doi.org/10.1016/B978-0-12-641750-0.50021-9

Zampieri, M. F. Continuous and alternate injection of water and polymer for enhanced oil recovery. Dissertação de Mestrado. Universidade Estadual de Campinas, Faculdade de Engenharia Mecânica, Campinas, 2012.

Zampieri, M. F.; Moreno, R., B., Z., L. Water injection, polymer injection and polymer alternating water injection for enhanced oil recovery - A laboratory study. Proceedings of the International Conference on Offshore Mechanics and Arctic Engineering - OMAE, Nantes, France, 914 June, 9p., 2013.

https://doi.org/10.1115/OMAE2013-10243
Zampieri, M.F.; Ferreira, V. H. S.; Quispe, C. C.; Sanches, K. K. M.; Moreno, R. B. Z. L. History matching of experimental polymer flooding for enhanced viscous oil recovery. Journal of the Brazilian Society of Mechanical Sciences and Engineering, v. 42, Article number: 205, 2020. https://doi.org/10.1007/s40430-020-02287-5

Zhang, G.; Seright, R. Effect of concentration on HPAM retention in porous media. Society of Petroleum Engineers. SPE Journal, v. 19(3), SPE166265-PA, 2014. https://doi.org/10.2118/166265-PA

Zheng, C. G.; Gall, B. L.; Gao, H.W.; Miller, A. E.; Bryant, R. S. Effects of polymer adsorption and flow behavior on two-phase flow in porous media. SPE/DOE Improved Oil Recovery Symposium, Paper SPE 39632, Tulsa, Oklahoma, 19-22 April 1998. https://doi.org/10.2118/39632-MS 